\title{
WORKING
}

paper

\section{Population Ageing and the Macroeconomy}

\section{Noëmie Lisack ${ }^{1}$ Rana Sajedi $^{2}$ \& Gregory Thwaites $^{3}$}

\author{
December 2019, WP \#745
}

\begin{abstract}
We quantify the impact of demographic change on real interest rates, house prices and household debt in an overlapping-generations model. Falling birth and death rates across advanced economies can explain much of the observed fall in real interest rates and the rise in house prices and household debt. Since households maintain relatively high wealth levels throughout retirement, these trends will persist as population ageing continues. Countries ageing relatively slowly, like the US, will increasingly accumulate net foreign liabilities. The availability of housing as an alternative store of value attenuates these trends, while raising the retirement age has limited effects.
\end{abstract}

Keywords: Demographics, ageing, natural interest rates, macroeconomic trends JEL classification: E21; E43; E13; J11

\footnotetext{
${ }^{1}$ Banque de France, 31 rue Croix des Petits-Champs, 75001 Paris, France, noemie.lisack@,banque-france.fr ${ }^{2}$ Bank of England, Threadneedle Street, London, EC2R 8AH, United Kingdom, rana.sajedi@bankofengland.co.uk

${ }^{3}$ LSE Centre for Macroeconomics, London School of Economics, Houghton Street, London, WC2A 2AE, United Kingdom, g.d.thwaites@1se.ac.uk

We are grateful to Pavel Brendler, Daisuke Ikeda, anonymous referees and seminar participants at the Banka Slovenije, Danmarks Nationalbank, the Riksbank, the International Monetary Fund, the Reserve Bank of Australia, the Center for Central Banking Studies, the Bank of England, the EUI Alumni Conference, the San Francisco Fed, the Money Macro and Finance Conference, and the DEGIT XXII Conference for their feedback. Remaining errors are ours.

Working Papers reflect the opinions of the authors and do not necessarily express the views of the Banque de France or the Bank of England. This document is available on publications.banque-france.fr/en
} 


\section{NON-TECHNICAL SUMMARY}

The population of advanced countries has aged rapidly over the past half-century, with life expectancy and the old-age dependency ratio having already reached unprecedented highs and projected to continue to rise for several decades. At the same time, long-term real interest rates have been on a downward trend, while house prices and household debt have risen dramatically. This paper quantifies the link between these important trends and examines the wider macroeconomic implications of demographic change using an overlapping-generations model calibrated for 23 advanced economies. We introduce demographic change as observed in the data in terms of cohort size and death probabilities and we solve for the transition path of the economy, assuming that ageing is the only exogenous change and is perfectly anticipated by the agents.

First, we compare the main outcome of our model, namely the natural real interest rate - the interest rate consistent with constant inflation and a closed output gap - to two empirical counterparts: the world real interest rate as estimated by Rachel and Smith (2017) and the model-based estimates of the natural interest rate from Holston et al. (2017).

\section{The real interest rate in advanced economies (\%)}

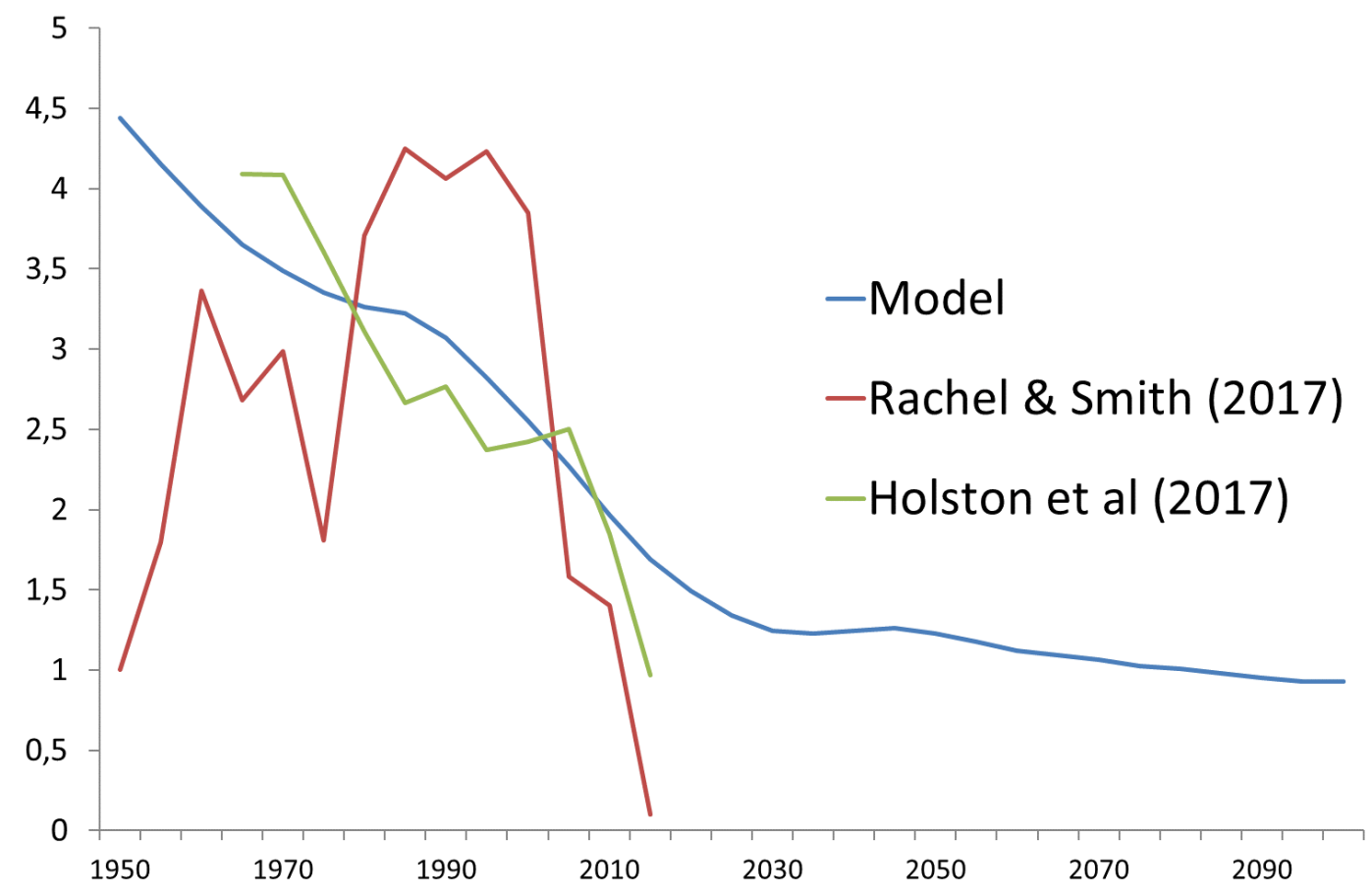

Holston et al. (2017) measures the natural interest rate, and is averaged across the US, UK, Euroarea and Canada. Rachel and Smith (2017) measures the world real interest rate. Sources: Rachel and Smith (2017), Holston et al. (2017) and author's calculations.

In the model, demographic change implies a decrease in the annual interest rate by 157 basis points (bps) between 1980 and 2015, and is forecast to push down interest rates by a further $76 \mathrm{bps}$ by 2100 . Compared to measures of the natural interest rate evolution between 1980 and 2015 obtained from the data, demographics are able to replicate $75 \%$ of the roughly 210bps drop estimated by Holston et al. (2017), and around 45\% of the fall in the Rachel and Smith (2017) measure.

The key mechanism triggered by the demographic transition is the following. First, households anticipate that they will live longer and spend more time in retirement. They are therefore willing to transfer more of their income during working life to the future, in order to smooth their consumption. Second, the slower population growth and increased longevity 
imply that older households make up a larger share of the total population alive at each period. These two changes both increase the level of aggregate savings-to-GDP over time. To keep the capital market balanced given this higher capital supply, the interest rate decreases.

Unsurprisingly, demographic change alone cannot explain the whole interest rate fall since 1980 which leaves room for other, possibly more transitory, explanations of the current low level of interest rates. Yet, the demographic changes themselves do not reverse, and leave the economy with a permanently lower natural interest rate, as highlighted by the slowly decreasing trend in interest rates after 2030.

Second, our theoretical set-up allows for a broader diagnostic on the impact of ageing on housing wealth, housing prices, household debt-to-GDP and external net foreign assets position. Besides the utility they derive from housing, households can use it as an additional way of transferring wealth over time, in that it is durable and can be sold to fund consumption and bequests. As the interest rate falls, demand for housing rises, pushing up housing prices and increasing the housing wealth-to-GDP ratio.

To be able to afford the more expensive housing assets, young households have to borrow more, and so the rising house price contributes to the rising household-debt-to-GDP ratio. The lower interest rate also has a similar effect as it encourages more borrowing by the young, raising net household debt-to-GDP. Although this pushes down on aggregate savings-toGDP, it is not strong enough to compensate the increase in savings implied by the change in the structure of the population, hence the increase in aggregate savings and decrease in interest rate along the transition path.

Last, extending our model to consider countries with different ageing speeds, we show that countries ageing faster (e.g. Germany) will accumulate positive net foreign assets, while the opposite is true for countries ageing at a slower pace. About $20 \%$ of the cross-country variations in net foreign assets-to-GDP can be explained by demographics in our model.

\title{
Les impacts macroéconomiques du vieillissement de la population
}

\begin{abstract}
RÉSUMÉ
À l'aide d'un modèle calibré à générations imbriquées, l'article quantifie l'impact des évolutions démographiques passées et futures sur les taux d'intérêt réels, les prix des logements et l'endettement des ménages. La baisse des taux de natalité et de mortalité dans les économies avancées peut expliquer en grande partie la baisse des taux d'intérêt réels mondiaux et la hausse des prix des logements et de l'endettement des ménages observées depuis les années 1980. Comme les ménages tendent à maintenir des niveaux de richesse relativement élevés tout au long de leur retraite, ces tendances persisteront à mesure que la population continuera de vieillir. Les pays qui vieillissent relativement lentement, comme les États-Unis, verront augmenter leur dette extérieure nette. Ces évolutions sont atténuées par la disponibilité du logement comme réserve de valeur alternative, tandis que le relèvement de l'âge de départ à la retraite a des effets limités.

Mots-clés : Démographie, vieillissement, taux d'intérêt naturels, tendances macroéconomiques

Les Documents de travail reflètent les idées personnelles de leurs auteurs et n'expriment pas nécessairement la position de la Banque de France ou de la Banque d'Angleterre. Ils sont disponibles sur publications.banque-france.fr
\end{abstract}




\section{Introduction}

The population of advanced countries has aged rapidly over the past half-century, with life expectancy and the old-age dependency ratio having already reached unprecedented highs and projected to remain high for several decades. At the same time, long-term real interest rates have been on a downward trend, while house prices and household debt have risen dramatically. This paper quantifies the link between these important trends and examines the wider macroeconomic implications of demographic change.

We build a calibrated neoclassical overlapping-generations (OLG) model to quantify the impact of these factors for advanced economies. We find that the ageing of the population in advanced economies can explain around $75 \%$ of the roughly $210 \mathrm{bps}$ fall in the Holston et al. (2017) measure of natural real interest rates between 1980 and 2015. Demographic pressures are forecast to reduce real interest rates a further 46bps by 2050. Furthermore, past falls in interest rates, along with the life-cycle pattern of housing demand, mean that demographics can explain more than four fifths of the $50 \%$ rise in real house prices between 1970 and the start of financial crisis. Given that the purchase of housing is predominantly carried out using household credit, these developments also explain the doubling of the household debt-to-GDP ratio over that same period.

Our main findings highlight that the concerns about future rises in real interest rates as baby-boomers retire are largely misplaced, for two main reasons. First, it is the stock of wealth, rather than the flow of saving, that determines the interest rate in neoclassical models, and this stock falls only slowly and partially over the course of retirement. The rise in the share of the population in high-wealth stages of life, starting from around age 50 according to the data, will therefore tend to raise the capital-output ratio even in the absence of any behavioural reaction to higher life expectancy. Therefore, we find that while the retired may dis-save, they still hold more wealth, and this higher stock pushes down on the interest rate. This is in contrast to the findings in Carvalho et al. (2016), and the arguments in Goodhart and Pradhan (2017). Second, population ageing is predominantly linked to a trend rise in life expectancy, rather than the transient rise in birth rates in the baby boom. The ongoing rise in life expectancy will, other things equal, tend to raise average wealth at any point in life as households anticipate needing to provide for a longer retirement. The ageing of the baby boom generation merely changes the timing of these long-run life expectancy effects.

While the size and timing of the effects we find are sensitive to model calibration and 
specification, the mechanism underlying our model is quite general. The rise in life expectancy tends to raise the capital-labour ratio: households save more for longer retirements and spend longer in high-wealth phases of their lives, and this extra wealth finds its way to firms and finances their capital investment. This pushes down on the marginal product of capital, which is a key determinant of the real interest rate. ${ }^{1}$ The fall in interest rates may encourage or dissuade further saving, thereby strengthening or weakening the effect of the original demographic shock. This depends on whether households' savings function slopes upward or downward.

We use our model to study the role that housing plays in mediating these effects. If productive capital is the only store of value, all of the burden is placed on capital to meet any increase in desired wealth holdings. So the presence of alternative stores of value can affect the impact of demographics on the interest rate. We show that, in practice, the presence of housing attenuates the fall in interest rates induced by demographic change, although the effects appear to be quantitatively small in our baseline calibration.

Using the heterogeneity by age and birth year within our model, we examine the implications of demographic changes for the level and distribution of welfare across time. Looking at expected welfare across cohorts over time, the main driver is increased longevity, which is conceptually difficult to quantify. Other than longevity, changes in life-time consumption are the main drivers of life-time utility, and seem to be detrimental to the baby-boom generation. Lower interest rates tend to increase welfare by allowing agents to better smooth consumption over their life-cycles.

Finally, we delve further into the open-economy dimension of our model by considering the demographic transition from the perspective of each country, taking the world interest rate as given. Specifically, while the world interest responds to the aggregate demographic trend, differences in the size and speed of demographic change across countries will lead to capital flows between countries. We show that demographics explain around $20 \%$ of the dispersion in advanced-economy net foreign asset positions. ${ }^{2}$ Given the difficulty of taking such a low-frequency model to time-series data, the explanatory power of the model in the cross-section gives us greater confidence in its predictions about the average level of interest rates in the global economy.

\footnotetext{
${ }^{1}$ In fact in a frictionless neoclassical models such as ours, the marginal product of capital is the only determinant of the real interest rate, while it could be one of several in a model with risk premia, financial frictions or price markups (Eggertsson et al., 2019; Caballero et al., 2017).

${ }^{2}$ Net foreign asset positions in the data are generally smaller in magnitude than the values predicted by our model, since the model ignores the presence of frictions in international capital flows.
} 
We do not claim that demographic change is the only influence on interest rates and other macroeconomic trends over the long run. In common with the other papers in this literature, our model is very stylised, and in particular does not include an account of the risk premia and financial frictions that may have caused the return on capital to diverge from government bond yields (see for example Marx et al., 2018; Caballero et al., 2017). The aim of this study is to isolate the effect of demographic change on savings behaviour and the real return on capital and other assets.

Our paper is one of several addressing the impact of demographic change on the real interest rate, house prices or external payments. Many papers focus only on a single economy: see for instance Kiyotaki et al. (2011), Gagnon et al. (2016), Eggertsson et al. (2019) on the United States or Waldron and Zampolli (2010) on the United Kingdom. Gagnon et al. (2016) and Eggertsson et al. (2019) model in detail the household's lifecycle, but relative to this paper they focus on the role of demographic change on the decline in the natural interest rate in the US, while Kiyotaki et al. (2011), conversely, focus on the effect of interest rates and demographics as drivers of land and housing markets. By considering all advanced economies together, instead, our paper relates to Carvalho et al. (2016) and Marx et al. (2018) and contributes to that literature by using a fully-fledged life-cycle model, examining the effects of demographics on house prices and household credit, as well as accounting more precisely for the high levels of wealth observed among older households, and highlighting the effect of this stock of wealth on the interest rate. Last, our open-economy exercise builds on Domeij and Flodén (2006), Krueger and Ludwig (2007) and Backus et al. (2014) who study international capital flows via current account movements. It is also related to the more recent work of Barany et al. (2018), who take into account country-specific borrowing constraints and social security. Here as well, our paper contributes to the literature by including housing as an alternative store of value, and by highlighting the importance of wealth stocks - and not only flows - for evaluating the impact of demographic change on the macroeconomy.

The remainder of this paper is structured as follows. Section 2 sets out the key demographic trends over the past few decades. Section 3 describes the model and its calibration. Section 4 shows the results of model simulations in which we incorporate the demographic trends, and considers some robustness exercises. Section 5 concludes. 
Figure 1: Ageing Population

(a) Population Shares by Age Group

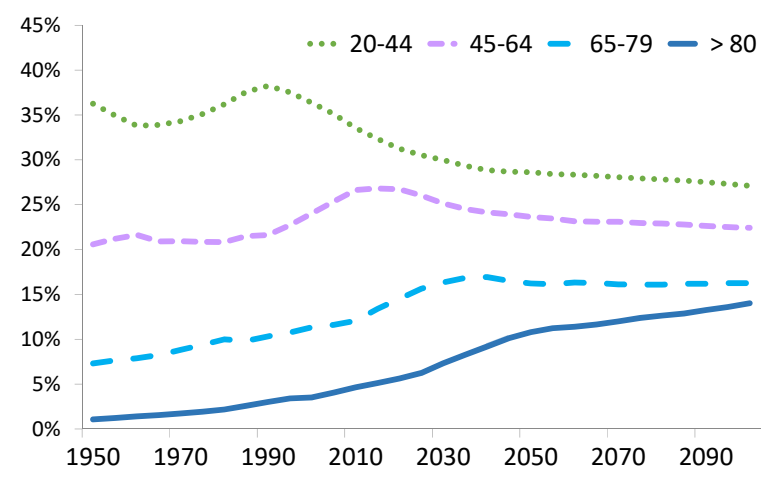

(b) Old-Age Dependency Ratio ( $\geq 65 / 20-64)$

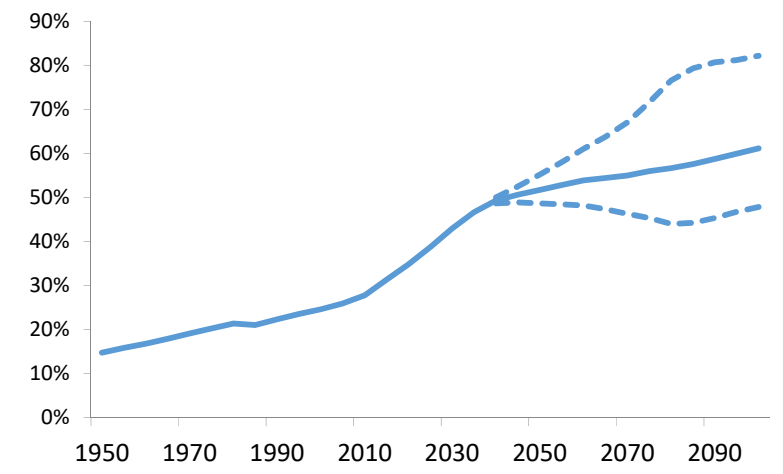

Source: UN Population Statistics (projections based on medium-fertility scenario, dashed lines in panel (b) show high- and low-fertility scenarios)

\section{Demographic Trends}

To document the key demographic trends that motivate this paper, we use data from the UN Population Statistics, which runs from 1950 to 2015, and includes projections up to 2100. Our focus is on an aggregate of advanced economies. ${ }^{3}$

The shares of different age groups in the total population over time, shown in Figure 1a, present two main patterns. Firstly, we see a clear rise in the share of older generations, for example with the over-80s going from $1 \%$ of the population in 1950 to around $5 \%$ in 2015, and reaching a projected $14 \%$ by the end of the century. Secondly, the effect of the baby boom shows as a 'bulge' moving through the population, entering the 20-44 age group from the 1970s and slowly disappearing by around 2040 .

This evolution is summarized by the old-age dependency ratio (henceforth OADR), shown in Figure 1b, defined as the ratio of over-65s to 20-64 year olds. Again the clear upward trend shows the rise in the share of older generations relative to the working population. The dashed lines, which show the alternative fertility scenarios in the UN projections, give an indication of the degree of certainty around the projections: even in the high-fertility scenario, the OADR increases substantially from around $15 \%$ in 1950 to almost $50 \%$ in 2100 . In the medium-fertility scenario the final number is over $60 \%$.

\footnotetext{
${ }^{3}$ In particular, we use Western Europe (Austria, Belgium, Denmark, Finland, France, Germany, Greece, Iceland, Ireland, Italy, Luxembourg, Netherlands, Norway, Portugal, Spain, Sweden, Switzerland and the UK), North America (Canada and the US), Japan, Australia and New Zealand.
} 
Figure 2: The Baby Boom

(a) Annual Growth Rate of Cohort Aged 20-24

(b) OADR Counterfactual
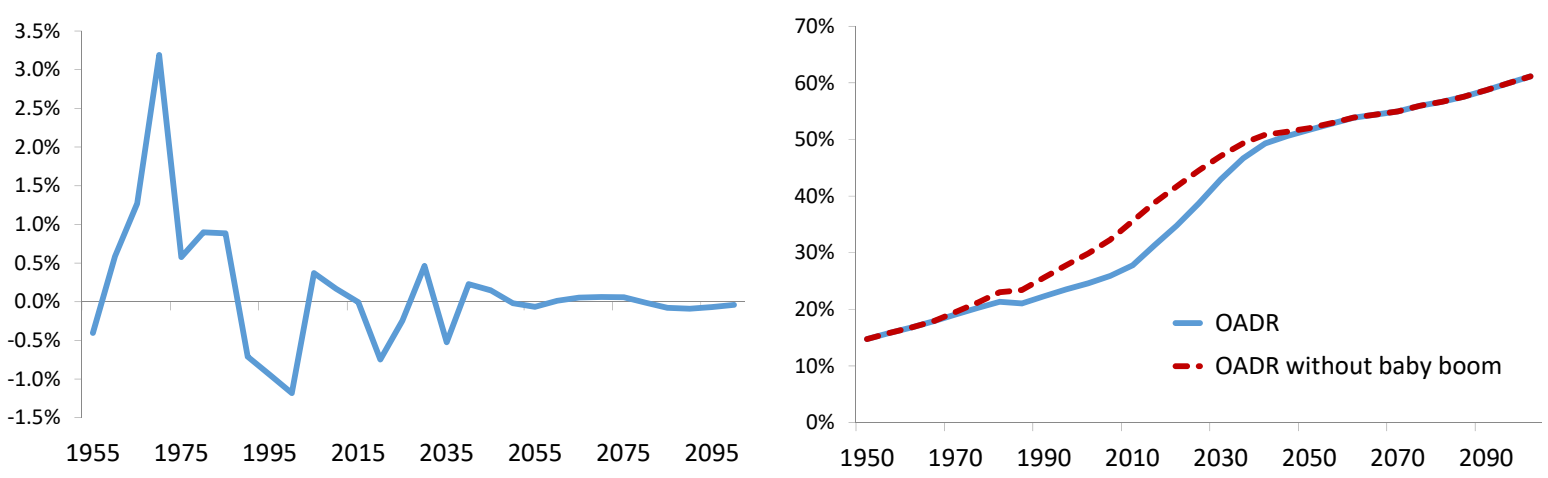

Source: UN Population Statistics (projections based on medium-fertility scenario)

Having documented these trends, we now examine their causes. Figure 2a shows the growth rate of consecutive 20-24 year old cohorts over time. We can see that the period 1970-1985 saw elevated growth rates, reaching over 3\% per annum, corresponding to the baby-boom generations born between 1945 and 1960. Growth rates have since fallen, and even been significantly negative for several periods. Both of these affect the age structure of the population. In particular, as the large baby-boom cohorts grow old, the age distribution becomes skewed towards the older age groups. This is amplified by the smaller size of the new younger generations entering the population.

To further illustrate the baby-boom effect on the aggregate demographic trends, Figure 2b shows the counter-factual OADR when we assume that cohort growth in 1970-1985 was zero, hence removing the effect of the baby boom. We can see that there is a nonnegligible effect from these cohorts. When they are young, and on the denominator of the OADR, they lower this ratio relative to the counter-factual. As they get older and begin to move to the numerator of the ratio, they account for a steeper rise in the OADR. Nonetheless, once these cohorts have faded out of the population, the counter-factual OADR reaches the same high levels as the baseline projections. Hence the baby boom does not account for the long run trend in the OADR.

The key determinant of the rise in the OADR is increasing longevity. Figure 3 shows life expectancy conditional on living to age $60 .{ }^{4}$ While a sixty year old in 1950 would not

\footnotetext{
${ }^{4}$ This measure is taken directly from the UN Population Statistics, and is defined as: "The average... years of life expected by a hypothetical cohort of individuals alive at age 60 who would be subject during the remaining of their lives to the mortality rates of a given period."
} 
Figure 3: Life Expectancy at 60

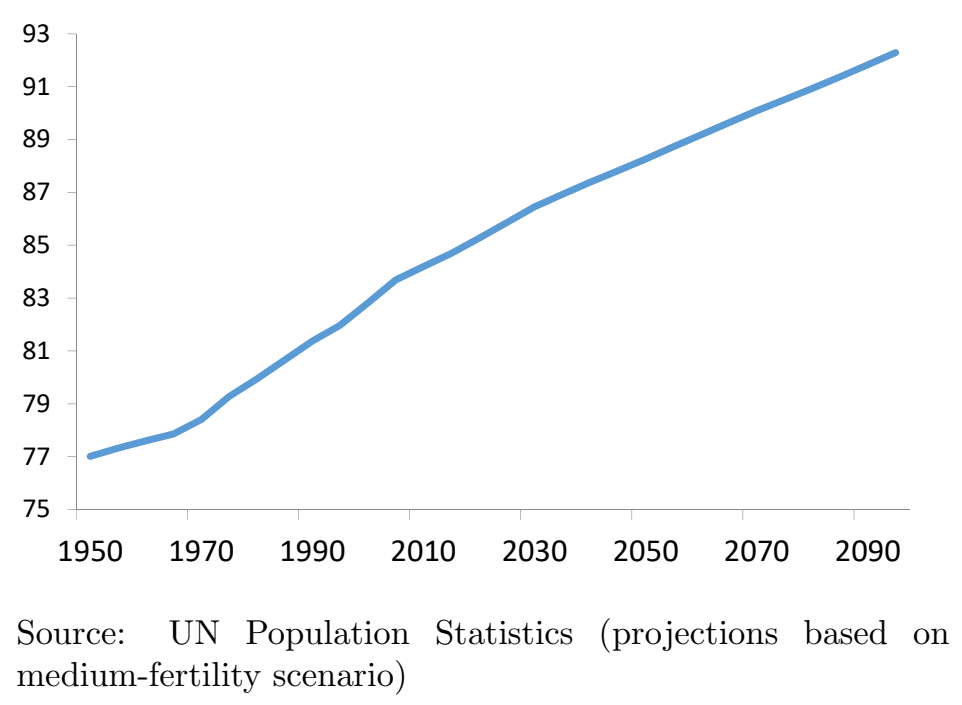

expect to live past the age of 77 , by 2015 a sixty year old can expect to live until close to 85. By the end of the century this number rises past 90. As people face lower mortality rates later in life, and their life expectancy rises, older age groups account for a growing proportion of the total population.

As this data makes clear, ageing population in advanced economies has led to an unprecedented shift in the age structure of the population, and these effects will almost certainly persist for decades to come. The rest of this paper will employ an OLG model to uncover the macro-economic effects of these important trends.

\section{Quantitative Model}

\subsection{The Model}

We consider a general equilibrium set-up with overlapping-generation households and a representative firm producing in a perfectly competitive environment. ${ }^{5}$ We describe these two agents in turn, and then describe the aggregation and market clearing conditions.

\footnotetext{
${ }^{5}$ The underlying model is the same as Sajedi and Thwaites (2016), allowing for demographic change.
} 


\section{Household}

Agents are born at age 1 and can live up to $T$ periods. We denote by $x_{\tau, t}$ the value of a variable $x$, for a household born in period $t$, when they are aged $\tau$.

Agents work from their first period of life until they reach retirement, at a fixed age $T^{r}$. They face a probability of death at (after) each age $\tau$, denoted $\left(1-\psi_{\tau, t}\right)>0$, and die with certainty at the maximum age, $T$, hence $\psi_{T, t}=0 \forall t$. This can be translated into the probability of surviving until each age, $\tilde{\psi}_{\tau, t}=\prod_{j=1}^{\tau-1} \psi_{j, t}$, with $\tilde{\psi}_{1, t}=1$.

Throughout their life, agents supply labour, $l$, inelastically, and gain utility from a consumption good, $c$, and a housing good, $h$, which is traded at relative price $p^{h}$. Hence the $T$-period optimisation problem faced by a representative household born in period $t$ can be written as

$$
\max _{\left\{c_{\tau, t}, a_{\tau, t}, h_{\tau, t}\right\}_{\tau=1}^{T}} \sum_{\tau=1}^{T} \beta_{\tau} \tilde{\psi}_{\tau, t}\left(\ln c_{\tau, t}+\theta_{\tau} \ln h_{\tau, t}\right)+\beta_{T} \tilde{\psi}_{T, t} \phi \ln a_{T, t}
$$

subject to

$c_{\tau, t}+a_{\tau, t}+p_{t+\tau-1}^{h}\left(h_{\tau, t}-h_{\tau-1, t}\right) \leq w_{t+\tau-1} \epsilon_{\tau} l_{\tau, t}+\left(1+r_{t+\tau-1}\right) a_{\tau-1, t}+\pi_{\tau, t} \quad$ for $\tau=1, \ldots, T$

where $\epsilon$ is the age-specific productivity level, $w$ is the wage per efficiency units of labour, and $a$ is a safe asset with return $r .{ }^{6}$ We assume that $l_{\tau, t}=\epsilon_{\tau}=0$ for $\tau \geq T^{r}$.

Agents are born without any assets, that is $a_{0, t}=0$, but we allow the possibility of bequests, setting $\phi>0$ so that $a_{T, t}>0$. These bequests are distributed among subsequent generations as part of $\pi_{\tau, t}$, which captures all non-labour income, taken as exogenous by the households.

There are a fixed number of periods when the household is able to "move house", i.e. re-optimise their housing wealth, and hence outside of these "move dates" the household has an additional constraint $h_{\tau, t}=h_{\tau-1, t} \cdot{ }^{7}$ We assume that agents are born without any housing wealth, and do not leave any housing wealth when they die, hence $h_{0, t}=h_{T, t}=0$, which necessitates $\theta_{T}=0$.

Denoting by $\lambda_{\tau, t}$ the Lagrange multiplier on the budget constraint at age $\tau$, this problem

\footnotetext{
${ }^{6}$ Note that $t+\tau-1$ is the period in which the generation born at time $t$ is aged $\tau$.

${ }^{7}$ This is a simple way to capture the fixed costs associated with buying and selling housing, which makes housing a less liquid asset.
} 
gives rise to the following first order conditions:

$$
\begin{aligned}
\lambda_{\tau, t}=\beta_{\tau} \tilde{\psi}_{\tau, t} c_{\tau, t}^{-1} & \forall \tau=1, \ldots, T \\
\lambda_{\tau, t}=\left(1+r_{t+\tau}\right) \lambda_{\tau+1, t} & \forall \tau=1, \ldots, T-1 \\
\lambda_{T, t}=\beta_{T} \tilde{\psi}_{T, t} \phi a_{T, t}^{-1} & \\
\sum_{j=\tau}^{\tau^{\prime}-1} \beta_{j} \tilde{\psi}_{j, t} \theta_{j} h_{\tau, t}^{-1}=p_{t+\tau-1}^{h} \lambda_{\tau, t}-p_{t+\tau^{\prime}-1}^{h} \lambda_{\tau^{\prime}, t} & \forall \tau \in \text { "move dates" }
\end{aligned}
$$

where $\tau^{\prime}$ in the last equation denotes the next move date after $\tau$.

\section{Firm}

The firm's problem is to choose the aggregate factors of production, $K_{t}$ and $L_{t}$, to maximise profit, taking as given the rental rate of capital, $r_{t}^{k}$, the wage per efficiency units of labour, $w_{t}$, and the production function, $Y=F(K, L)$. Note that $L_{t}$ denotes the aggregate efficiency units of labour supplied by households. This problem can be written as

$$
\max _{L_{t}, K_{t}} F\left(K_{t}, L_{t}\right)-w_{t} L_{t}-r_{t}^{k} K_{t}
$$

Taking the CES production function $F(K, L)=\left[(1-\alpha) L^{\frac{\sigma-1}{\sigma}}+\alpha K^{\frac{\sigma-1}{\sigma}}\right]^{\frac{\sigma}{\sigma-1}}$, we have the following first order conditions ${ }^{8}$

$$
\begin{aligned}
& w_{t}=(1-\alpha)\left(\frac{Y_{t}}{L_{t}}\right)^{\frac{1}{\sigma}} \\
& r_{t}^{k}=\alpha\left(\frac{Y_{t}}{K_{t}}\right)^{\frac{1}{\sigma}}
\end{aligned}
$$

Capital is financed from the households savings and depreciates at rate $\delta$ every period. Before paying for the capital rental rate, the firm is left with $\left(1-\delta+r_{t}^{k}\right) K_{t}$ at the end of each period $t$ and the households receive an interest rate $r_{t}$ on their savings, hence the zero profit condition of the firm implies

$$
r_{t}^{k}=r_{t}+\delta
$$

${ }^{8}$ Although changes in TFP growth over time may partly explain changes in real interest rates, we abstract from this in order to focus on the role of demographics. Instead, below, we will look at how demographic changes affect labour productivity due to the age-specific productivity levels. 


\section{Aggregation}

We denote the gross growth rate of the generation born at time $t$ relative to the generation born at time $(t-1)$ with $g_{t}$. Normalising the size of the generation born at time 0 to 1 , this means the size of the generation born at time $t$ can be written as

$$
s_{t}=g_{t} s_{t-1}=\prod_{i=1}^{t} g_{i}
$$

At each age, the size of the cohort reduces, with survival probability $\tilde{\psi}_{\tau, t} \leq 1$. Hence the total population in period $t$ is given by

$$
S_{t}=\sum_{\tau=1}^{T} \tilde{\psi}_{\tau, t-\tau+1} s_{t-\tau+1}=\sum_{\tau=1}^{T} \tilde{\psi}_{\tau, t-\tau+1} \Pi_{i=1}^{t-\tau+1} g_{i}
$$

Let $\mathbf{x}_{t}$ denote the $(T \mathrm{x} 1)$ vector of a variable $x$, for one representative household of each generation alive at time $t$, in other words $\mathbf{x}_{t}=\left\{x_{\tau, t-\tau+1}\right\}_{\tau=1}^{T}$. Let $\rho_{t}$ denote the $(T \mathrm{x} 1)$ vector of population sizes at time $t$, that is $\rho_{t}=\left\{\tilde{\psi}_{\tau, t-\tau+1} s_{t-\tau+1}\right\}_{\tau=1}^{T}$. The aggregate value of variable $x$ at time $t$ is denoted by $X_{t}=\rho_{t}^{\prime} \mathbf{x}_{t}$. We denote by $\tilde{X}_{t}$ the value of $X_{t}$ per aggregate capita, that is $X_{t} / S_{t}$. We can write this as $\tilde{X}_{t}=\tilde{\rho}_{t}^{\prime} \mathbf{x}_{t}$ where $\tilde{\rho}_{t}=\rho_{t} / S_{t}$ denotes the vector of relative population sizes.

\section{Market Clearing}

Capital/Savings Market The value of the capital stock must equal the aggregate savings of the previous period

$$
A_{t-1}=K_{t}
$$

As introduced above, we denote per capita capital stock as $\tilde{K}_{t}=K_{t} / S_{t}$. For consistency, this implies that per capita savings are defined relative to next period's population, that is $\tilde{A}_{t}=A_{t} / S_{t+1}=\frac{S_{t}}{S_{t+1}} \tilde{\rho}_{t}^{\prime} \mathbf{a}_{t}$.

Labour Market Aggregate labour supply must equal labour demand. Let $\epsilon \mathbf{l}_{t}=$ $\left\{\epsilon_{\tau} l_{\tau, t-\tau+1}\right\}_{\tau=1}^{T}$ denote the vector of efficiency units of labour supplied by each generation at time $t$. Then

$$
\rho_{t}^{\prime} \epsilon \mathbf{l}_{t}=L_{t} \quad \Rightarrow \quad \tilde{\rho}_{t}^{\prime} \epsilon \mathbf{l}_{t}=\tilde{L}_{t}
$$


Housing Market As with the household savings, for consistency we define per capita housing relative to next period's population, that is $\tilde{H}_{t}=H_{t} / S_{t+1}=\frac{S_{t}}{S_{t+1}} \tilde{\rho}_{t}^{\prime} \mathbf{h}_{t}$. Housing is effectively residential land, in that its supply is inelastic, hence we assume that the housing stock per capita is fixed at some level, $\tilde{H} \cdot{ }^{9}$ Market clearing then simply requires

$$
\tilde{H}_{t}=\tilde{H} \quad \forall t
$$

This implies that the aggregate housing stock, $H_{t}$, grows with the population, meaning that the economy is endowed with an additional $\left(\frac{S_{t+1}}{S_{t}}-1\right) \tilde{H}$ units of housing each period. ${ }^{10}$ This endowment is distributed across households through non-labour income, along with the bequests, as detailed below.

Bequests and Non-labour Income At each time $t$, the non-housing assets and the housing wealth of the generations that died in the previous period, as well as the additional housing endowment, added in each period to maintain a stable level of housing per capita, are distributed to living households through bequests (see Appendix A.1 for more details). This non-labour income is evenly distributed among households above a given age, $T^{b}$, while younger households are not entitled to any non-labour income. ${ }^{11}$

Goods Market Aggregating the budget constraints of all households alive at a given time $t$, and substituting the equilibrium conditions described above, gives us the familiar resource constraint

$$
\tilde{Y}_{t}=\tilde{C}_{t}+\tilde{I}_{t}
$$

where $\tilde{I}_{t}$ is the net increase in aggregate savings, given by

$$
I_{t}=A_{t}-(1-\delta) A_{t-1} \quad \Rightarrow \quad \tilde{I}_{t}=\frac{S_{t+1}}{S_{t}} \tilde{A}_{t}-(1-\delta) \tilde{A}_{t-1}
$$

\footnotetext{
${ }^{9}$ This is in line with Knoll et al. (2017), who find that the bulk of the increase in house prices is attributable to the increase in the value of residential land.

${ }^{10}$ The alternative would be to allow this additional housing to be produced, with a technology which transforms the consumption good into housing. This does not materially affect the results, as discussed in Section 4.3 and in Appendix C.1.

${ }^{11}$ This assumption is aimed to reflect the fact that older households are more likely to see their family members die and to inherit their assets and housing wealth. Furthermore, a flat bequest distribution across households above this age ensures that bequests do not create strong distortions on the household consumption and saving choices.
} 
Hence the resource constraint above simply implies that all goods produced at time $t$ are either consumed or saved as capital.

\subsection{Calibration}

Each period in the model represents 5 years. We assume that working life begins at age 20 and no agents live beyond age 90 , setting $T=14$.

The focus of our calibration will be (i) to match life-cycle profiles of labour productivity, housing wealth and net worth, and (ii) to match aggregate housing wealth-to-GDP, debtto-GDP and real interest rates. All of these moments will vary over time in the dynamic transition path due to the demographic trends. Hence we must target these moments at particular points in time. Given the data availability, we target average life-cycle patterns for the years 1990-2010. For the aggregate moments, we target their average values over the 1970s, in order to allow the model to determine the transition over the past few decades. Full details of the calibration procedure are provided in Appendix A.2.

\subsubsection{Demographic Transition}

Population growth, $g_{t}$, and the survival probabilities, $\psi_{\tau, t}$, are the exogenous demographic processes that drive fluctuations in our model. Using the data described and shown in Section 2, we set these two series so as to match the evolution of the age structure of the economy from the 1950s, and projected until 2100.

Specifically, we set $g_{t}$ as the relative size of consecutive 20-24 year old cohorts over time. We then set $\psi_{\tau, t}$ to match the observed evolution of each cohort throughout their life, meaning that the rate of decline in the size of a given cohort from one period to the next is taken to be the death rate. ${ }^{12}$

\footnotetext{
${ }^{12}$ The existence of immigration means that cohort sizes can go up as well as down over time, particularly for younger age groups. To remove this possibility, we smooth the death rate before retirement to match the overall decline of a given cohort between the ages of 20 and 64 . If a cohort size is higher at the age of 64 than at the age of 20 , which is the case for more recent years, we assume a zero probability of death before retirement.
} 


\subsubsection{Data}

\section{Life-cycle Profiles}

Given limited cross-country data availability, we will assume that US households are representative of all advanced-economy households in terms of the life-cycle profiles of labour productivity, housing wealth and net worth. Hence, we can use the Survey of Consumer Finance (SCF) to match life-cycle profiles for productivity, $\epsilon$, net worth, $a$, and housing wealth, $h$.

Specifically, we calibrate productivity to match "Wage Income" data from the SCF, which corresponds to total labour income, irrespective of hours worked. Hence, since hours worked are inelastic in the model, we are effectively subsuming all life-cycle hours and wage decisions into the productivity profile. To calibrate housing wealth over the life-cycle, we take the sum of "Primary Residence" and "Other Residential Real Estate" in the SCF. We then subtract this from the total "Net Worth" to obtain non-housing $\operatorname{assets} a .^{13}$

\section{Aggregate Variables}

We take three aggregate variables as targets: the real interest rate, housing wealth-toGDP and debt-to-GDP. In order to allow the model to determine the evolution of these variables over the last few decades, we target their average value in the 1970s.

For the real interest rate we use the data from Holston et al. (2017), and take the average world interest rate between 1970-1980. This gives us a target of $3.42 \%$.

The data from Piketty and Zucman (2014) measure housing assets, including land, and give us the aggregate housing wealth-to-GDP target. We take an average over the 1970s for all available countries, namely Australia, Canada, France, Germany, Italy, Japan, the UK and the US. We obtain a target ratio of $147 \%$.

Finally for debt-to-GDP we use the BIS Total Credit data, focusing on total credit to households as a percentage of GDP. Again we use the average over the 1970s for the

\footnotetext{
${ }^{13}$ See Appendix A.3 for details. Note that by matching labour income and assets, consumption over the life-cycle will be determined residually by the household budget constraint, and so it is not being matched to data.
} 
countries available, in this case Canada, Germany, Italy, Japan, the UK and the US. The final target is $40 \%$.

\subsubsection{Other Parameters}

We set the parameters of the CES production function $\sigma=0.7$ and $\alpha=1 / 3$, and the annualised depreciation rate $\delta=6 \%$.

We set hours worked at 0.3 throughout working life, hence $l_{\tau}=0.3$ for $\tau=1, \ldots, T^{r}-1$, and $l_{\tau}=0$ for $\tau \geq T^{r}$. Hence aggregate labour supply is $L=0.3$, the value commonly used in the literature. Households are assumed to retire at age 65, corresponding to $T^{r}=10$. They start receiving bequests at age $T^{b}=7$, i.e. age 50 .

In matching the life-cycle profile of housing wealth, we set the "move dates" in the household's problem to $\tau=1,5,11$, corresponding to ages 20, 40 and 70 . The final period of life will also be a "move dates" as we have assumed that agents do not leave housing bequests.

\subsubsection{Calibration Outcomes}

Figure 4 shows the life-cycle profiles for productivity, housing and net worth from the data and the model. For the model, given that these profiles change over time in the transition, we take the equivalent of the estimates from the data, namely the average of the cross-sectional age-profile of each variable over 1990-2015. The aggregate moments are matched exactly by construction.

To show how well we fit the demographic trends with the growth rate and death probabilities as exogenous series, Figure 5a shows the OADR of the model against the data. Figure 5b plots a slightly different ratio, which we call the high-wealth ratio (HWR). To define this ratio, we use the empirical life-cycle profile of assets to define the 'high-wealth' phase of an agents life. As can be seen from Figure 4b, agents have accumulated a large amount of wealth by around the age of 50-55, and maintain that level of wealth until the end of their life at the age of 90 . Hence we define the HWR as the ratio of those over 50 to those aged 20-49. Looking at Figure 5, we see that, despite the simplifications that we make, both the OADR and the HWR in the model are very close to that in the data. $^{14}$

\footnotetext{
${ }^{14}$ Note that the data line here ignores the population over 90 , in line with the model, and so the
} 
Figure 4: Calibration of Life-cycle Profiles

(a) Labour productivity by age

(b) Net worth (excluding housing) by age

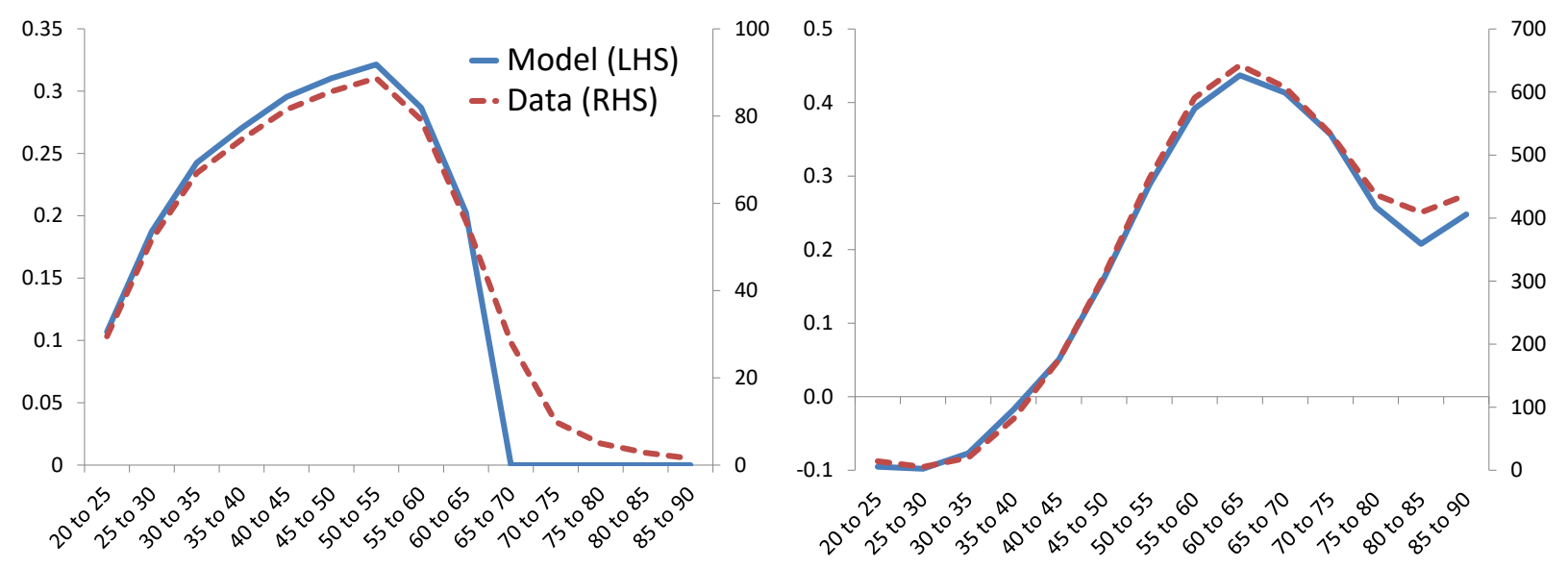

(c) Housing wealth by age

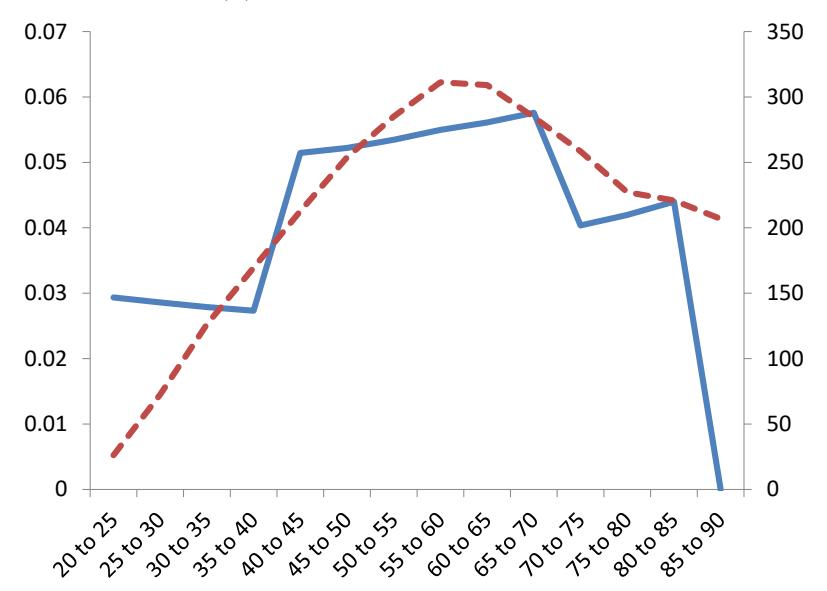

Model lines are relative to the expected life-time labour income of the 1950 cohort Data lines are Thousands of US Dollars 
Figure 5: Demographics in the Model vs Data

(a) Old-Age Dependency Ratio

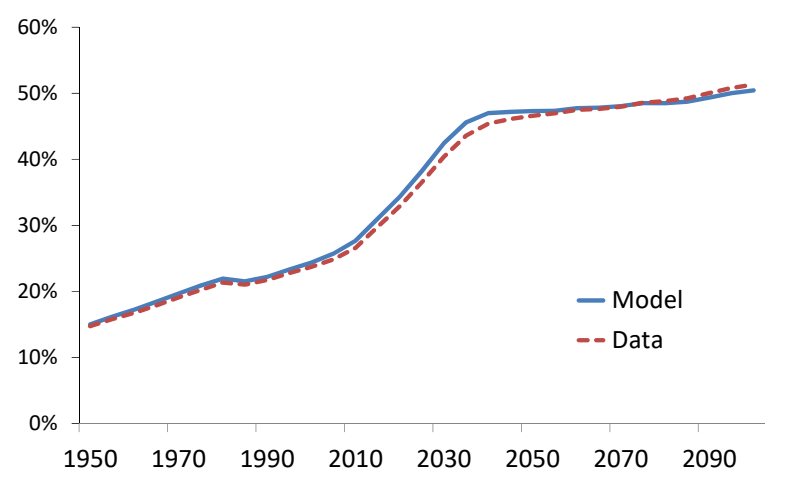

(b) High Wealth Ratio

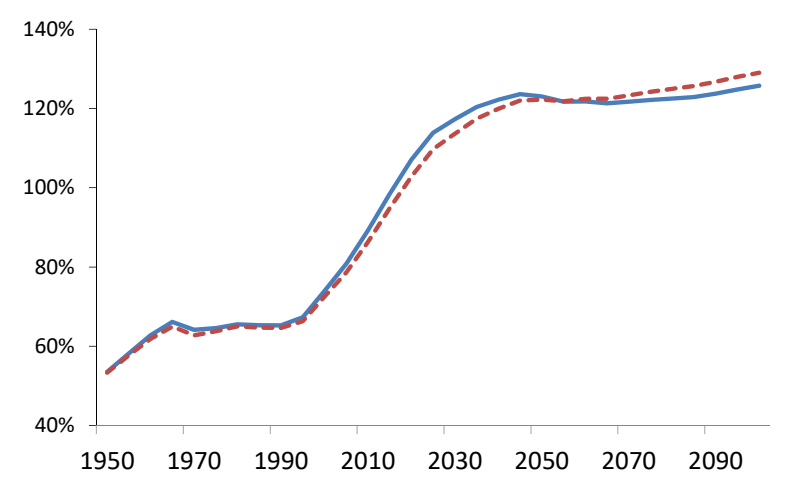

Source: UN Population Statistics and own calculations.

\section{Results}

We now present the results of the model simulations. Given the exogenous demographic changes described above, we solve for the general equilibrium transition path of the economy, assuming perfect foresight. We show the transition of the main macroeconomic variables of interest, namely the real interest rate, savings and debt, and decompose these results in terms of the changes in the age distribution of the population and changes in the savings behaviour of households as they expect to live longer. We then explore other macroeconomic implications of demographic trends: on the housing market, labour productivity, welfare and distribution, and in an open economy context. To facilitate the comparison with the model outcomes, all data points shown in the figures are 5year averages. Finally, we carry out some robustness exercises to further investigate our results.

\subsection{Baseline Results}

\subsubsection{The Interest Rate, Savings and Debt}

First, we turn to the main outcome of our model, namely the real interest rate, compared to its empirical counterparts. Given that we are using a real model, the real interest rate here should be interpreted as the natural real interest rate: the interest rate that prevails

OADR does not rise as much as in Figure 1. 
Figure 6: The Real Interest Rate (\%)

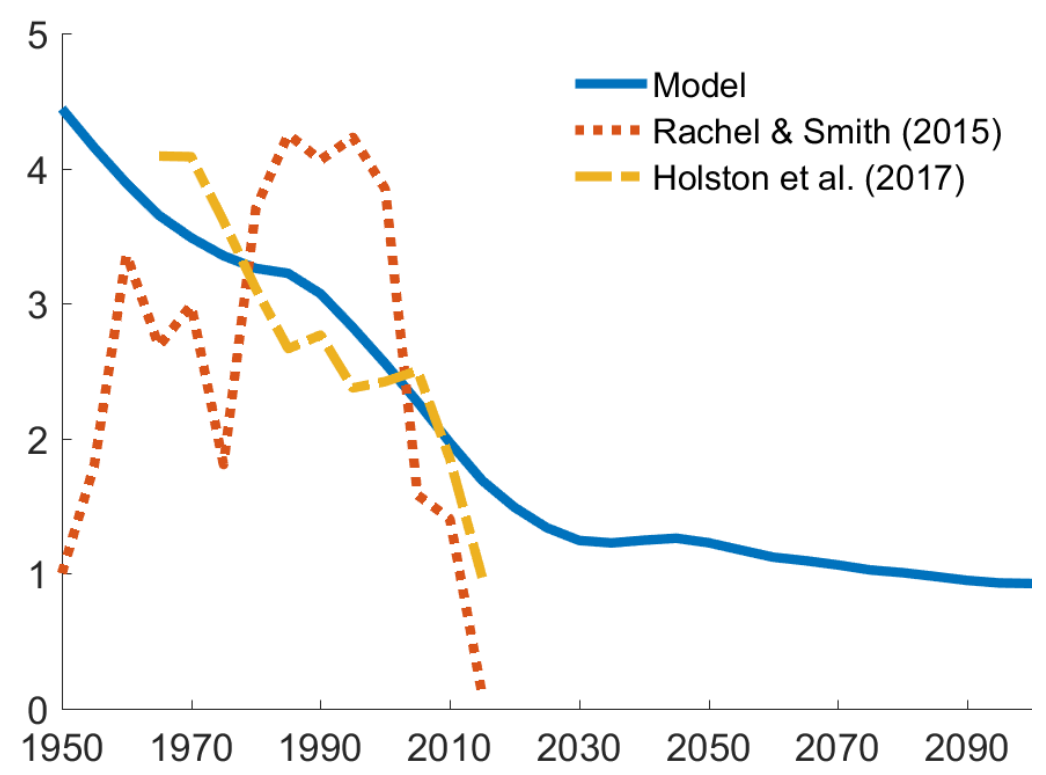

Holston et al. (2017) measures the natural interest rate, and is averaged across the US, UK, Euro-area and Canada. Rachel and Smith (2017) measures the world real interest rate.

in the absence of nominal rigidities, or equivalently the interest rate that is consistent with inflation at its target and the output gap closed over the medium to long run. This object is not directly observable, but in Figure 6 we show the model outcome against two empirical estimates that are available for advanced economies. Namely, the red dotted line shows the average advanced-economy long-run real interest rate, based on 10-year sovereign yields, taken from Rachel and Smith (2017), and the dash-dotted yellow line shows the model-based estimate of the natural interest rate from Holston et al. (2017). These measures of real interest rates are clearly more volatile than the long-term natural interest rate that is captured by the demographic trends in our model. ${ }^{15}$

In the model, the annual interest rate decreases by $157 \mathrm{bps}$ between 1980 and 2015. ${ }^{16}$ Compared to the empirical counterparts, between 1980 and 2015, demographics are able to explain $75 \%$ of the roughly 210 bps drop estimated by Holston et al. (2017), and around $45 \%$ of the fall in the Rachel and Smith (2017) measure. These empirical measures have fallen by more than is predicted by our model through demographic changes, leaving

\footnotetext{
${ }^{15}$ To facilitate the comparison with the model outcomes, all data series shown in the next sections are 5 -year averages.

${ }^{16}$ Since we have calibrated the level of the real interest rate in the 1970 s, we focus here on the changes since 1980.
} 
room for other more transitory explanations of the current low level of interest rates. Nonetheless, it is important to note that the demographic changes themselves do not reverse, and leave the economy with a permanently lower natural interest rate. In the transition path, it is still possible to see the transitory impact of the baby boom, slowing down the interest rate decrease in the 1990s and accelerating it between 2010 and 2040 . However, in the long run, the main driver behind the transition path is the increase in life expectancy, as mentioned in Section 2, and this trend is projected to persist. The real interest rate in our model is forecast to decrease by a further 46bps by 2050 and 76 bps by 2100 .

The converse of the fall in the real interest rate is a rise in the capital stock, shown in Figure 7a against two empirical measures of capital intensity: an index of capital servicesto-GDP for 19 advanced countries, in the red dotted line, and an index of the ratio of the capital stock to value added in the US business sector from the Fernald (2012) data, in the yellow dash-dotted lines. The demographic trends alone slightly over-estimate the rise in capital, particularly for the US, as we abstract from other factors that drive investment. Nonetheless, both measures of capital intensity show a rise, particularly in the period of interest since the 1980s. This gives credence to the notion that part of the fall in the real interest rate is the standard neoclassical effect of a rise in the capital intensity of the economy.

The key mechanisms triggered by the demographic transition is the following. Firstly, households perfectly anticipate that they will live longer and spend more time in retirement. They are therefore willing, all things equal, to transfer more of their income during working life to the future, in order to smooth their consumption. Secondly, the slower population growth and increased longevity imply that older households make up a larger share of the total population alive at each period. Were households not anticipating their longer life-time and adjusting their consumption and saving choices, this change in population weights would still change aggregate savings and aggregate consumption outcomes. In partial equilibrium, these two mechanisms would both increase the level of aggregate savings-to-GDP over time. In general equilibrium, to keep the capital market balanced given this higher capital supply, the interest rate decreases. This lower interest rate has an offsetting effect as it discourages savings, and even encourages more borrowing by the young, raising net household debt-to-GDP, and pushing down on aggregate savings-to-GDP. As shown in Figure 7b, household debt-to-GDP rises in the model in line with the data. 
Figure 7: Capital and Debt

(a) Capital Stock-to-GDP (\%)

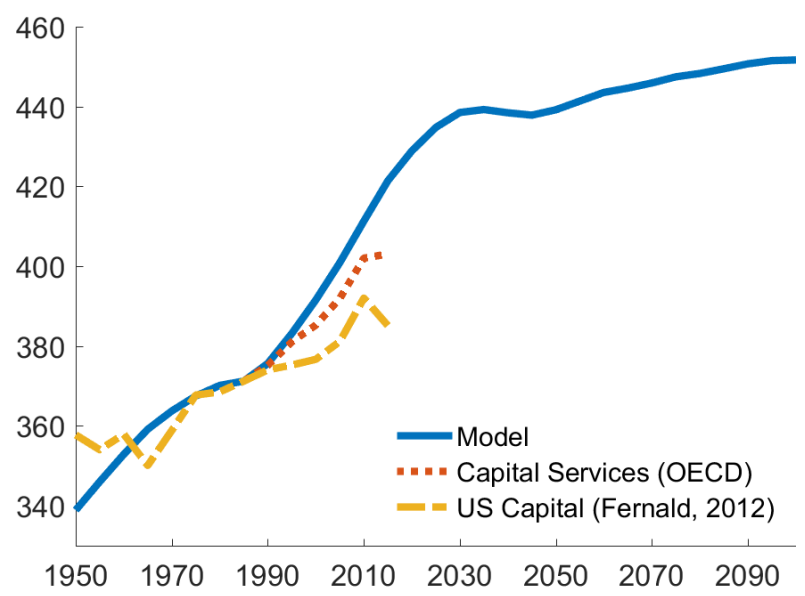

(b) Household debt-to-GDP (\%)

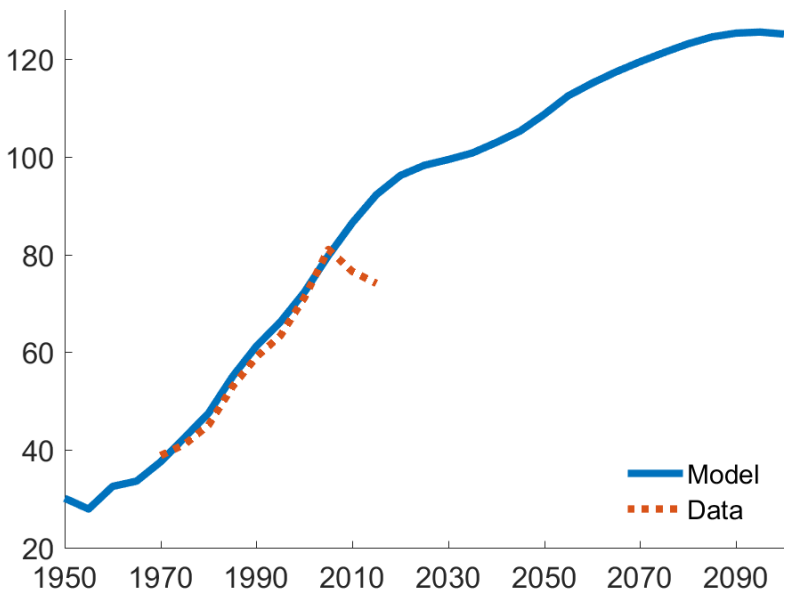

Sources: Capital services are measured by OECD data for Australia, Austria, Belgium, Canada, Denmark, Finland, France, Germany, Ireland, Italy, Japan, Korea, Netherlands, New Zealand, Portugal, Spain, Sweden, United Kingdom and the United States. US capital is from Fernald (2012). Household debt is from BIS databases; the household debt-to-GDP is the ratio of household debt to nominal GDP.

We can see the effects of these two mechanisms by decomposing the changes in aggregate savings into the two distinct drivers: changes in the age composition of the population and changes in the life-cycle savings decisions of each household, given the new general equilibrium prices. The impact of these two distinct drivers on aggregate savings and household debt is shown in Figure 8. ${ }^{17}$ The marginal impact of changes in the population age structure (shown in the red dotted line) on aggregate savings per capita tends to be larger than the baseline: indeed, it only takes into account the smaller (resp. larger) share of younger (resp. older) households in the total population. Since older households hold more assets, increasing their share in the economy drives up the level of aggregate savings per capita. Similarly, only younger households are indebted, so that the aggregate household debt-to-GDP decreases with the decreasing share of young households in the economy.

Conversely, taking only changes in optimisation over the life-cycle into account, shown in the dash-dotted yellow line, the aggregate savings per capita actually decrease massively from 1990 onwards: since the interest rate is lower, and despite their increased life expectancy, households shift their portfolio towards consuming more, holding more housing

\footnotetext{
${ }^{17}$ See Appendix B.1 for the details of the construction of this decomposition and a second exercise separating between partial and general equilibrium effects on household decisions.
} 
Figure 8: Decomposing the Drivers

(a) Aggregate Savings-to-GDP

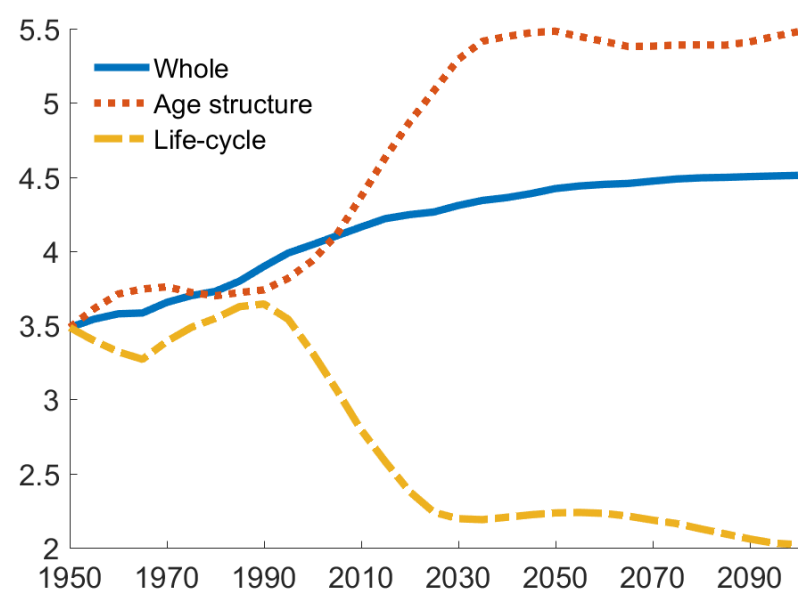

(b) Household debt-to-GDP (\%)

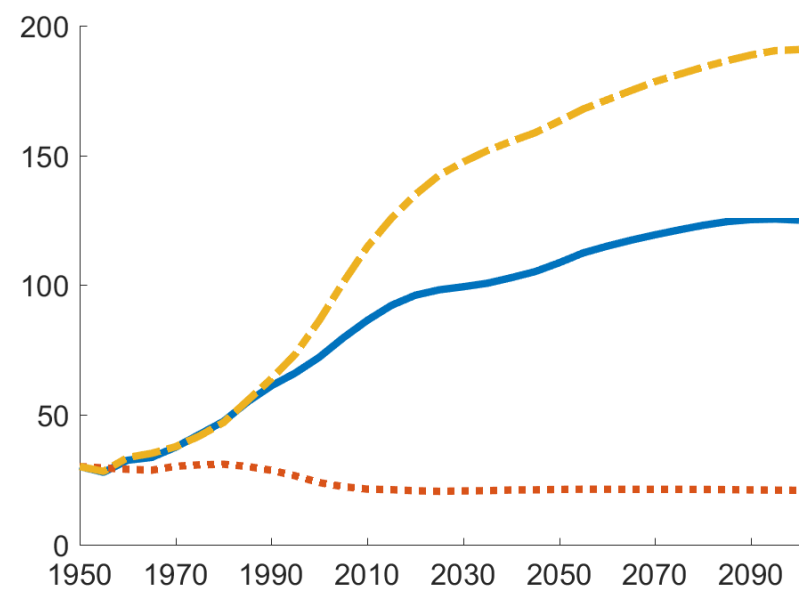

Age structure is changing only the population age structure and Life-cycle is changing only the household's optimal behaviour.

wealth, and more debt when young. Without the offsetting effect of the falling share of the increasingly-indebted young in the population, this leads to a fall in aggregate savings.

We conduct a similar decomposition exercise for household debt-to-GDP, as shown in Figure $8 \mathrm{~b}$. We reach similar conclusions to the aggregate savings case: the changes in the population structure tend to stabilise or decrease the household debt-to-GDP, while the household re-optimisation of their consumption, savings and borrowing decisions given their increased life expectancy and the lower interest rate implies an higher debt-to-GDP ratio.

\subsubsection{Housing}

One important feature of our model compared to the literature is the presence of housing. Households directly derive utility from housing, but housing also serves a second purpose, as households can use it as an additional way of transferring wealth over time, in that it is durable and can be sold to fund consumption and bequests. In our framework, households have perfect foresight, which allows them to anticipate the evolution of the housing price over their life-time, and therefore anticipate the return on housing as a store of wealth over their life-cycle. As the interest rate falls, so does the user cost of housing, 
Figure 9: Housing in the Baseline Simulations

(a) Real house prices (\% deviation from 1970)

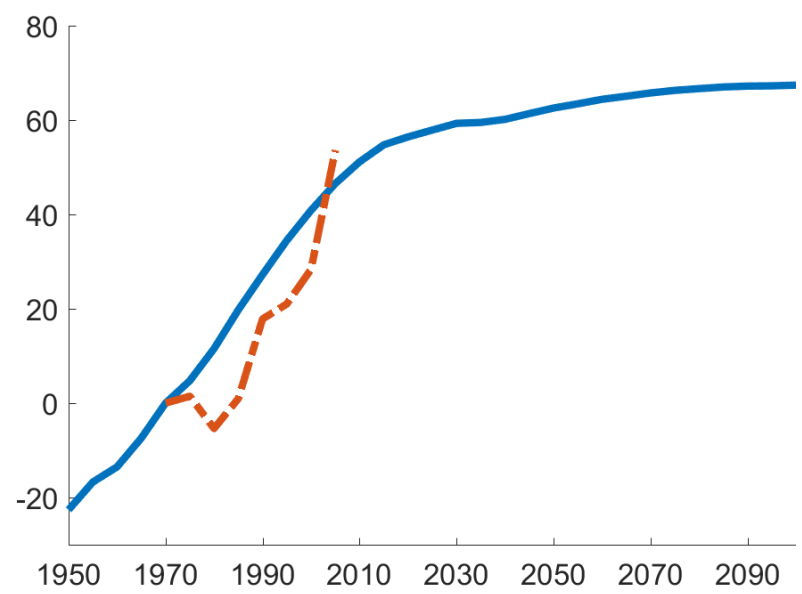

(b) Housing wealth-to-GDP (\%)

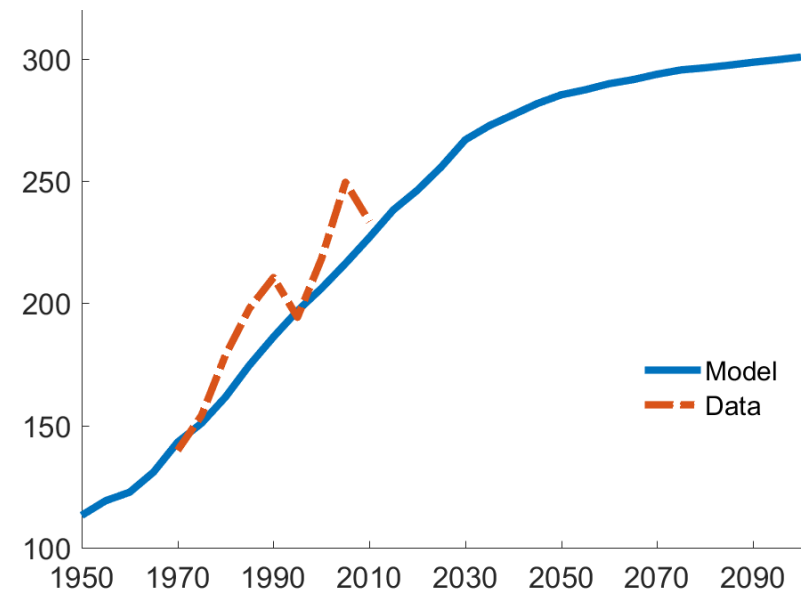

Sources: Housing wealth comes from Piketty and Zucman (2014). Real house prices are from the BIS databases and are the ratio of nominal house prices to the consumer price index.

which is the opportunity cost of investing into an additional unit of housing instead of the financial asset, and so demand for housing rises. With the supply of housing per capita held fixed in our model, housing prices are pushed up, and, as a consequence, housing wealth-to-GDP ratio increases, as shown in Figure 9. In fact, we are able to explain $85 \%$ of the observed increase in real house prices. ${ }^{18}$ To be able to afford the more expensive housing assets, young households have to borrow more, and so the rising house price also contributes to the rising debt-to-GDP ratio. Housing accordingly provides an alternative vehicle for the transfer of resources over the life-cycle, and will raise interest rates.

Still, the evolution of house prices does not follow the real interest rate one for one. In our model, the households are only allowed to move (change their housing wealth) at specific ages. This has two implications. Firstly, it means that the house price is sensitive to changes in the relative size of different cohorts as they move from buying to selling housing. This means that the baby boom plays an important role in dynamics of house prices. In 2015, the oldest households from the baby-boom generation (born between 1945 and 1950) reach age 70, so that the share of the group aged 40 to 69 in the total population starts decreasing, while the share of the group aged 70 to 84 picks up. Concretely, the share of households with the highest housing demand, the 40-69 year

\footnotetext{
${ }^{18}$ This can be seen as an upper bound on this effect, since any increase in housing supply per capita would mitigate the rise in house prices.
} 
Figure 10: User cost of housing and forward looking interest rate

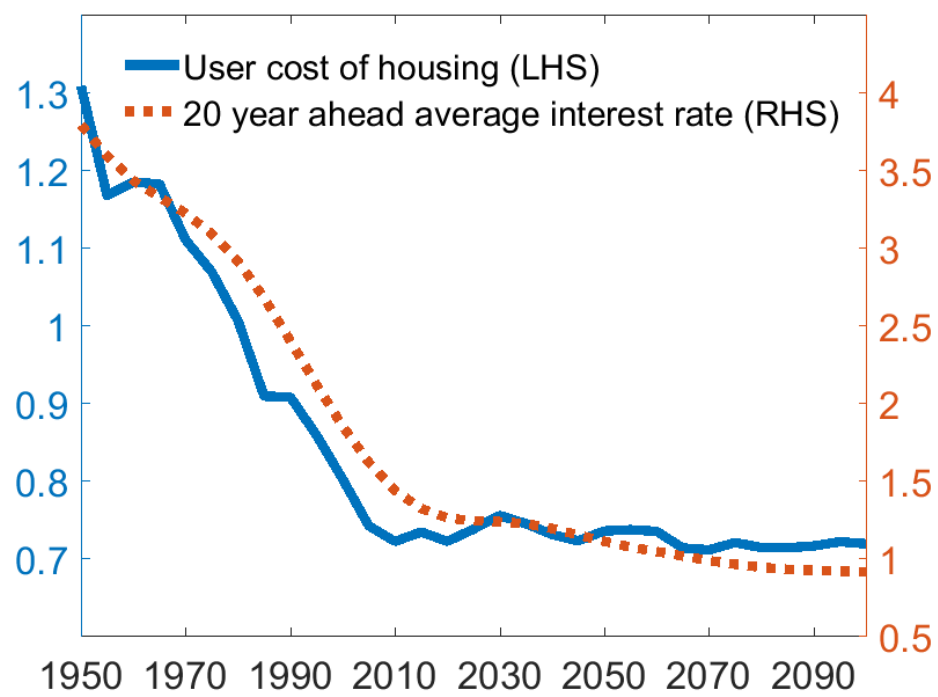

The user cost of housing is the product of the interest rate and the house price, less the capital gain on the house.

olds, decreases, while the share of households with a lower housing demand, aged 70 and over, increases. Consequently, even as the demographic transition continues, the rise in housing demand slows down around this time, and hence house prices flatten out. ${ }^{19}$

The second implication of the discrete move-dates is that, as a savings instrument, housing has a longer maturity than capital, meaning that house prices are more forward looking: households buying housing know that they will have to wait between 15 and 30 years before being able to sell it. The user cost of housing, therefore, reflects expected future changes in prices (both the interest rate and the housing price). This is shown in Figure 10, which plots the four-period (20-year) ahead average real interest rate against the per-period user cost of housing. These variables follow the transition of house prices more closely than the real interest rate.

\subsubsection{Productivity}

While we abstracted from trend productivity growth as a driver of macroeconomic trends, our model can partially explain the observed movements in labour productivity through the effect of demographic changes. As shown on Figure 4a, the productivity of young

\footnotetext{
${ }^{19}$ See Appendix C.1 for more details.
} 
Figure 11: Implications of Demographic Trends for Productivity

(a) Average age of working population

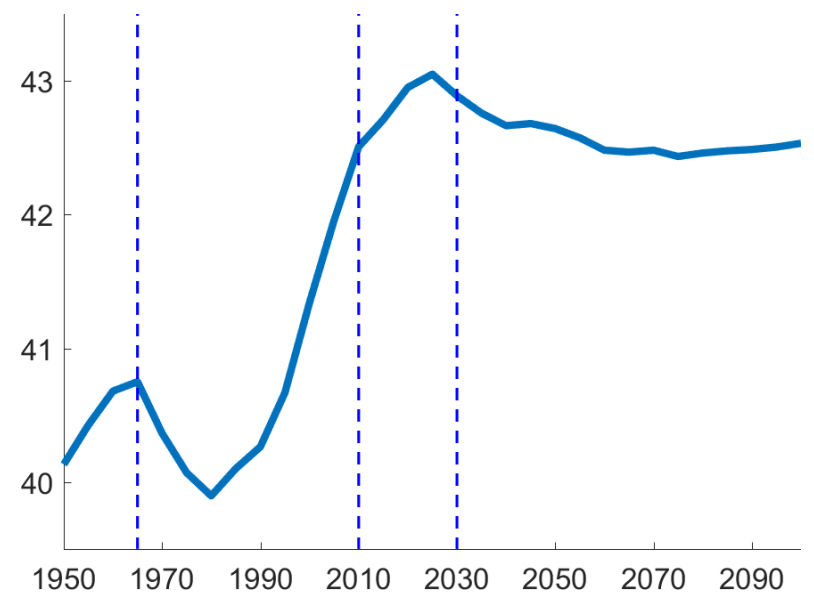

(b) Annual productivity growth (\%)

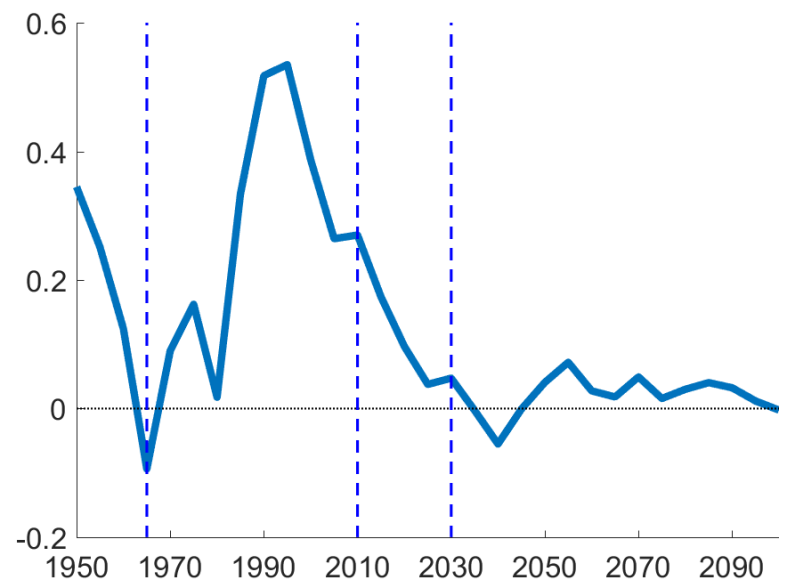

Vertical dashed lines show when the oldest baby-boom generation enter the workforce, retire, and reach age 90 .

and old workers is lower, and productivity reaches its peak around age 50. Hence, a change in the age distribution of the working population implies a different level of the aggregate productivity.

The evolution of the average age of the working population in our model and the resulting productivity growth rate are shown on Figure 11. We can clearly see the impact of the baby-boom generation on the figures. From 1970 onwards, the young baby-boomers start working, bringing down the average age of the working population and hence productivity growth. Until 2000, the baby-boomers age and gain in work experience, increasing the labour force's average age and productivity. From 1990, the baby-boomers generation reaches ages 50 and above, their productivity decreases and hence the productivity growth slows down, while the average age of the working population keeps increasing. Finally, from 2015 onwards, the baby-boom generations start retiring progressively. The average age of the working population decreases slowly, and productivity growth slows down further. While demographic changes are not the only explanation for the recent slow-down in productivity growth, our model shows that the ageing workforce may have played a role in this evolution. 


\subsubsection{Distributional Impact of Demographic Change}

Since our model includes heterogeneity in terms of birth year and age, we can measure inequality along two dimensions: across households within period, and across cohorts defined by their birth year. It is important to emphasise, however, that our model is not designed to analyse inequality from either a positive or a normative angle - there is no within-cohort heterogeneity, and there are conceptual difficulties in comparing welfare over changing lifespans. ${ }^{20}$ Our results accordingly should not be read as a full intergenerational welfare analysis. Nonetheless, it is interesting to see what insights we can get from the model about distributional impact of demographic changes.

Within-period Inequality Figure 12 shows the evolution of Gini coefficients for consumption and financial, housing and total wealth implied by our model from 1950 onwards. As above, there are two main drivers of this evolution: the direct effect of the changing age structure and the equilibrium effect of the changing life-cycle profiles of each variable. For consumption, these two components work in the same direction. As agents become older, the age structure is more concentrated, lowering the dispersion of consumption and hence lowering the Gini coefficient. At the same time, the lower interest rate allows households to borrow and consume more when young, while older households tend to consume less as they expect to live for longer. Again this lowers the dispersion of consumption across agents and lowers the Gini coefficient.

For wealth inequality the trend is more muted, as the two drivers work in opposite directions. The initial increase from 1965 to 1990 as well as the post-2030 increase are mostly due to a more unequal wealth distribution across households, with younger agents being more indebted and middle-aged agents holding higher financial wealth. These higher levels of debt and savings are the flip-side of the consumption smoothing described above. Between 1990 and 2030, however, the age composition effect offsets this: the share of poorer, younger households in the total population decreases, while the share of richer, older households increases, thus stabilizing the Gini coefficient for a few decades. The increase in housing wealth inequality implied by the model after 2020 is due to similar factors. The share of households aged above 70 increases strongly between 2020 and 2045. These households tend to hold less housing, as they sell back part of it to finance their retirement consumption. As a consequence, the distribution of housing

\footnotetext{
${ }^{20}$ Furthermore, we use model-implied rather than actual relative prices in order to isolate the impact of demographic change, and ignore, as elsewhere in this paper, the impact of other drivers in the data.
} 
Figure 12: Gini coefficients

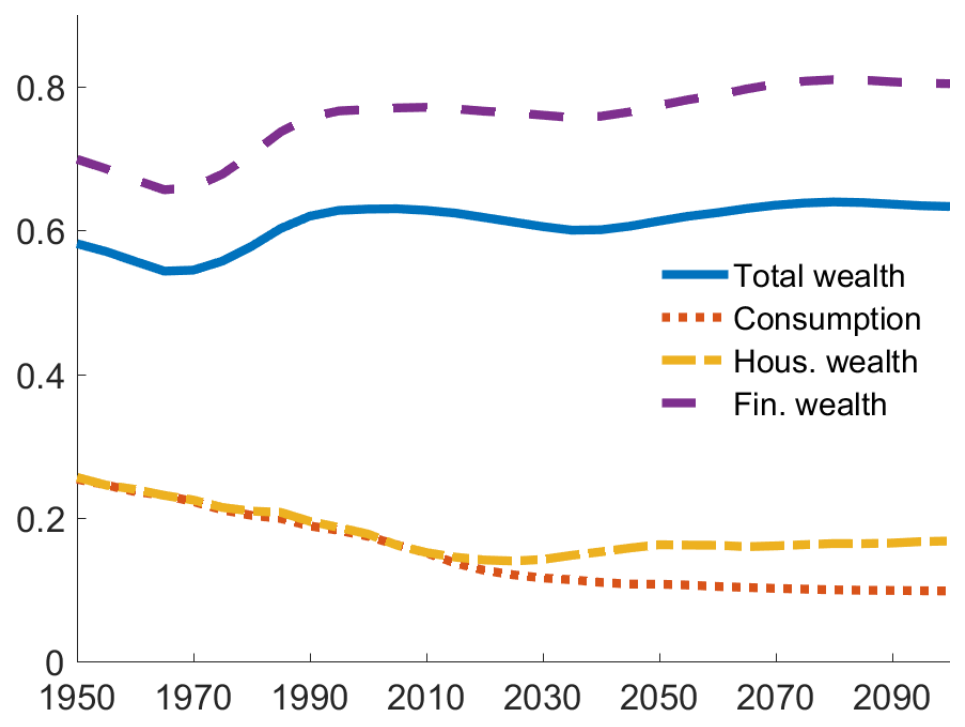

in the population becomes more unequal, increasing the associated Gini coefficient.

Inequality Across Cohorts In our model, cohorts differ across several dimensions: their size and life expectancy according to exogenous demographic trends, but also consumption, wealth and housing levels given by general equilibrium outcomes. If simply comparing expected life-time utility across cohorts, we would find a clear increase over time, meaning that an agent born in 1980 has a higher expected utility than one born in 1950. This is however the simple consequence of increased longevity and hence being able to enjoy consumption over a longer period of time, and necessarily depends on underlying assumptions regarding the value of being alive rather than dead.

To obtain a meaningful comparison, it is necessary to disentangle the various components at play, most importantly to abstract from the change in longevity. To do this, we use the decomposition suggested by Jones and Klenow (2016), which allows us to subtract the longevity component of utility from the total utility variation. ${ }^{21}$ The result is shown in the blue solid line in Figure 13, in consumption equivalents with respect to the 1950 cohort. This is actually equivalent to comparing utility across cohorts, keeping the death probabilities fixed at the level of the 1950 cohort. $^{22}$ Once abstracting from longevity effects, the change in realised utility across cohorts is much smaller and

\footnotetext{
${ }^{21}$ Full details of this exercise are provided in Appendix B.2.

${ }^{22}$ The choice of the cohort here affects the precise magnitude of the utility differentials between cohorts, but does not affect the overall dynamics.
} 
Figure 13: Decomposition of Expected Life-time Utility (Consumption Equivalents, \%)

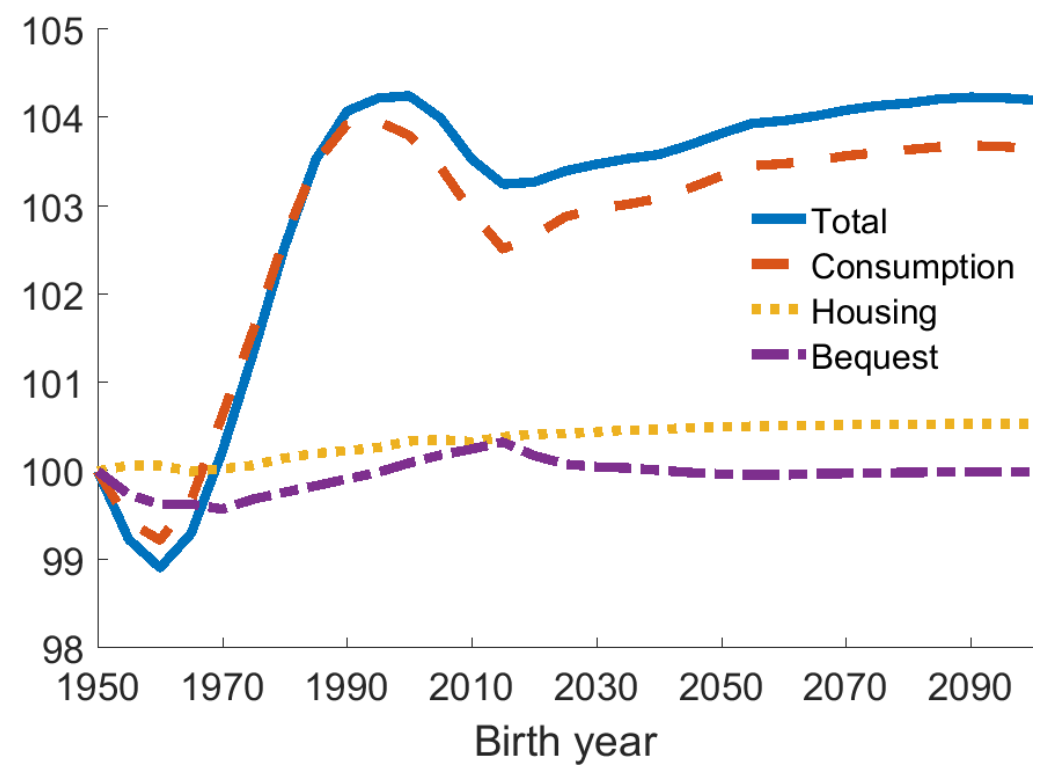

Death probabilities fixed at 1950-cohort level

does not monotonically increase, with baby-boomers and households born around 2015 appearing to be worse off.

We can further decompose this total utility across components related to housing, bequests and consumption in the dashed lines in Figure $13 .^{23}$ The consumption component is clearly the main driver, with both the magnitude and dynamics looking very similar to total utility. The contribution of housing utility slightly increases for later cohorts, due to a better distribution of housing over the life-cycle, allowed both by the increased ability of young households to borrow and buy housing, and by the changes in the age distribution of the population. The overall contribution of housing utility remains very small, however, as its share in total utility is small (less than $2 \%$ ). Finally, the contribution of utility gained from leaving bequests to the next generations does not show any clear trend over time, and is anyway very small. ${ }^{24}$

Examining income differences across cohorts is another way to understand the origins of their welfare differences. While total income is relatively stable across cohorts, Figure 14 shows that this is hiding an increase in labour income and a decrease in capital, housing

\footnotetext{
${ }^{23}$ Each component is an aggregate of the level and 'smoothing' component in the Jones and Klenow (2016) methodology; see Appendix B.2 for the full decomposition.

${ }^{24}$ The bequests line corresponds to the additional utility from leaving bequests included in the households' utility function, and not to the utility gains obtained by the households receiving the bequests.
} 
Figure 14: Life-time income and its components

(a) Absolute values

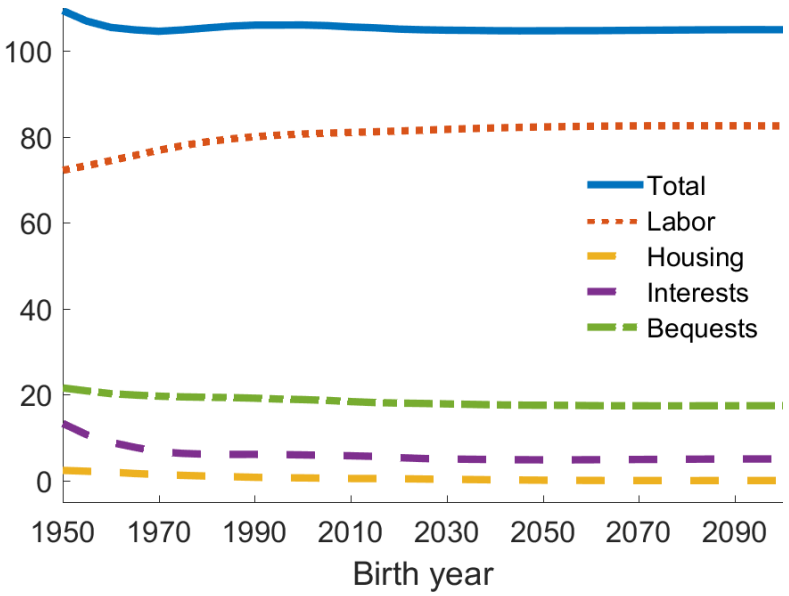

(b) Normalised to 1 in 1950

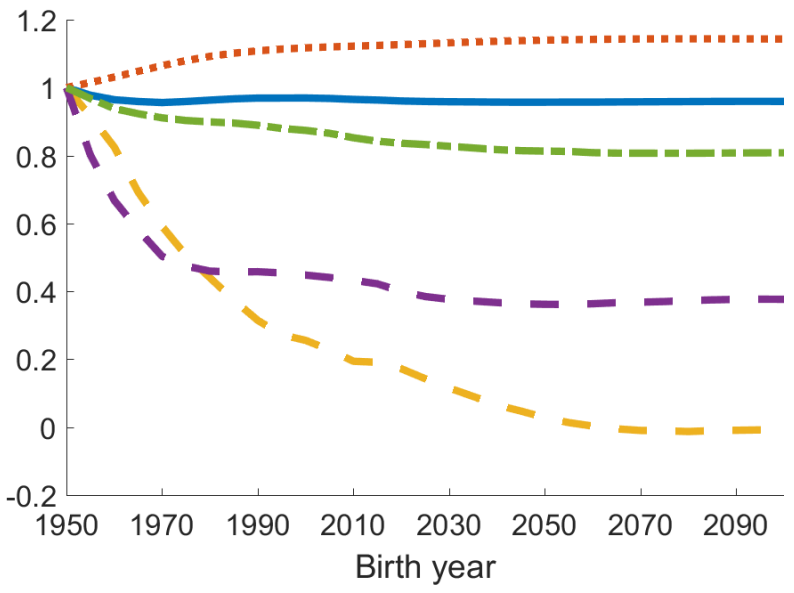

and bequests income. Because of the decrease in interest rates and the progressive slow down in housing prices, income from housing and interest on capital drops dramatically. Their aggregate impact remains small however, because housing and interest only account for a small share of total income. ${ }^{25}$

To conclude, increasing longevity implies an increase in welfare, but its impact is difficult to measure. Abstracting from longevity, changes in life-time consumption are the main drivers of realised utility, and seem to be detrimental to the baby-boom generation. The effect of capital gains from housing are lower than one might expect. Finally, an improved consumption smoothing across age, thanks to lower borrowing costs, is found to have a non-negligible positive impact on welfare.

\subsection{Open Economy Implications}

So far we have considered the group of advanced economies as one closed economy, and looked at the effects of the demographic trends in the aggregate population. While an ageing population is common to all these countries, different countries within this group are ageing at different speeds. Figure 15 shows the OADR for a handful of countries

\footnotetext{
${ }^{25}$ Interest income is equal to the net capital share, which is the product of the capital-output ratio, which ranges between 3 to 4 , times the annual real interest rate, which ranges between $1 \%$ and $4 \%$. As shown in Figure 9 housing wealth increases by around 1\% of GDP per year from 1950 to 2030, and then flattens off. Accordingly, these capital gains cannot form a large share of any generation's permanent income, though they accrue disproportionately to the early baby-boom generation.
} 
within our aggregate group. As can be seen, Japan and Germany, for example, are ageing much faster than the aggregate, while the UK and US are ageing more slowly.

Figure 15: OADR Across Countries

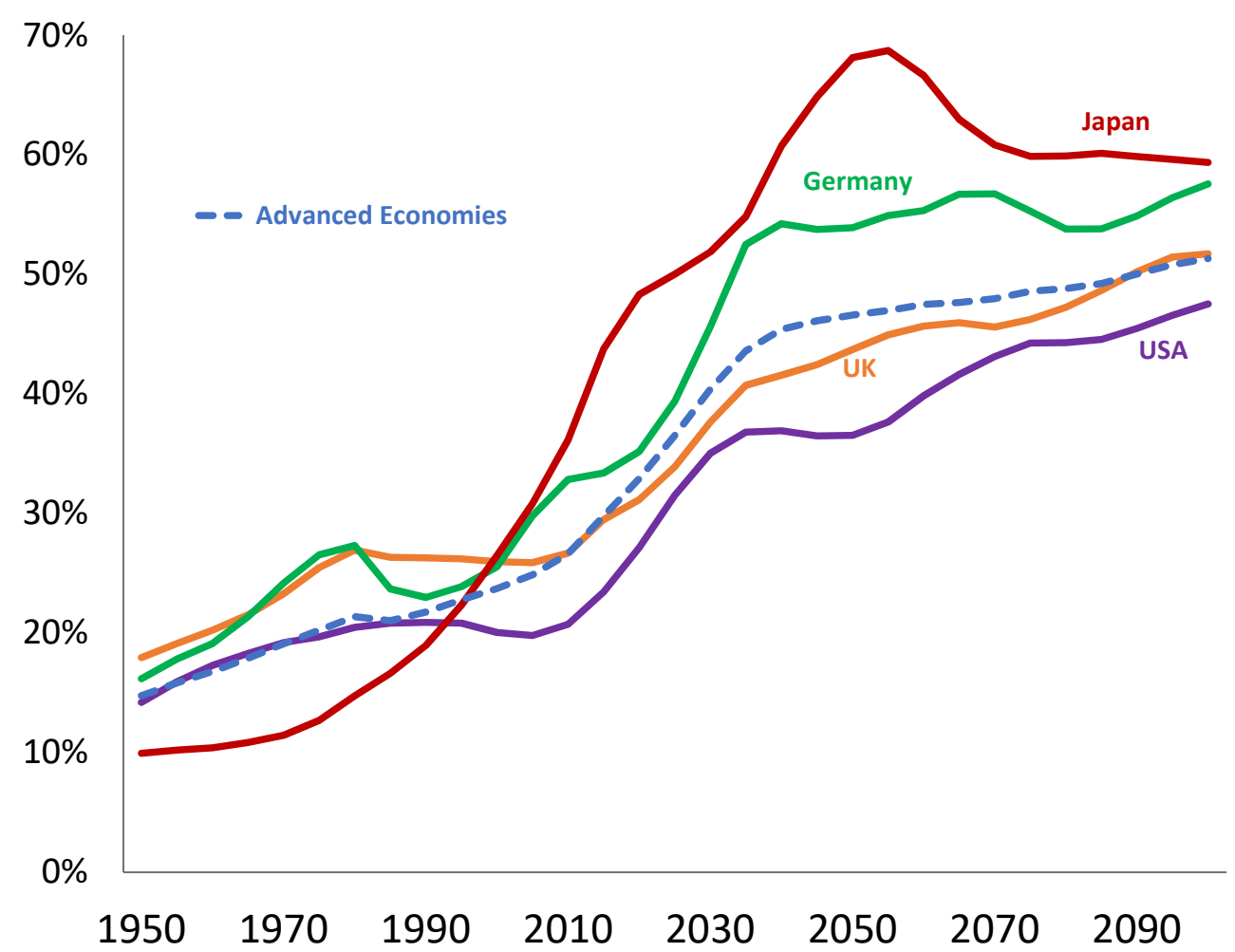

Source: UN Population Statistics (projections based on medium-fertility scenario)

How can our model account for these differences? Consider each of these countries as a small open economy trading on fully integrated global capital markets. In other words, each country takes as given the global real interest rate that arises in the aggregate. All else equal, this means that the firms in each country demand the same level of capital relative to output, which can be seen from their first order condition. There is, however, no market-clearing condition for the domestic capital markets, implying that household savings can be above or below the capital demanded by firms. This discrepancy between domestic savings and domestic capital gives rise to a non-zero net foreign asset (NFA) position for the domestic economy. In particular, if domestic savings are higher than domestic capital, then domestic households must place their savings into capital abroad. Conversely, if domestic capital is higher than domestic savings, some of the domestic capital must be owned by foreign households. 
Consider a country such as the US, which is ageing more slowly than the average. There, demographic trends are putting less upward pressure on savings, and hence the global real interest rate is below the interest rate that would arise were the US a closed economy. In other words, the savings of domestic households in the US is below the desired capital level of US firms. This translates to a negative NFA position for the US, as capital flows into the US from foreign households. Conversely, for a country such as Germany, which is ageing faster than the average, the global interest rate is above the rate that would balance the domestic capital market, and this translates to capital outflows from Germany and the accumulation of foreign assets by German households.

To quantify this, we can solve for equilibrium in a small open economy version of the OLG model, where the interest rate is exogenous and instead of the capital market clearing condition, we have an equation that defines net foreign assets

$$
\widetilde{N F A_{t}}=\tilde{A}_{t-1}-\tilde{K}_{t}
$$

We solve this version of the model dynamically with the exogenous path of the real interest rate set as the path of the real interest rate from the aggregate exercise, as shown in Figure 7, and feeding in the demographic variables of a given country. ${ }^{26}$

Figure 16 plots the level of the NFA-to-GDP ratio in 2015 against the predicted level from the model across all the countries in our advanced-economies group. This exercise can be interpreted as a test of the mechanisms of our model against the data. The model omits any frictions in the international movement of capital, such as capital controls or home-bias in portfolio allocations, which were an important feature of the world economy at least in the early post-war period. ${ }^{27}$ Hence we see that the model predicts slightly larger NFA positions than we observe in the data, with the trend line in this scatter plot being somewhat shallower than the 45 degree line. Nonetheless, a substantial part of the cross-country differences in NFAs can be explained by the model looking only at differences in demographics. This gives us greater confidence about the mechanisms underlying all of the results from our model. ${ }^{28}$

\footnotetext{
${ }^{26}$ Notice that, so long as we keep the parameters of the model the same for each country, taking the path of the interest rate from the closed economy exercise is equivalent to solving the model as a multicountry world economy with perfectly integrated capital markets, abstracting from country-specific differences in real interest rates.

${ }^{27}$ The simulations also assume that the economy is always at the dynamic equilibrium, omitting, for example, the major fiscal and physical consequences of the Second World War

${ }^{28}$ See Appendix B.3 for more details on individual countries' NFA paths and model predictions.
} 
Figure 16: NFA-to-GDP in the Model vs Data (2015)

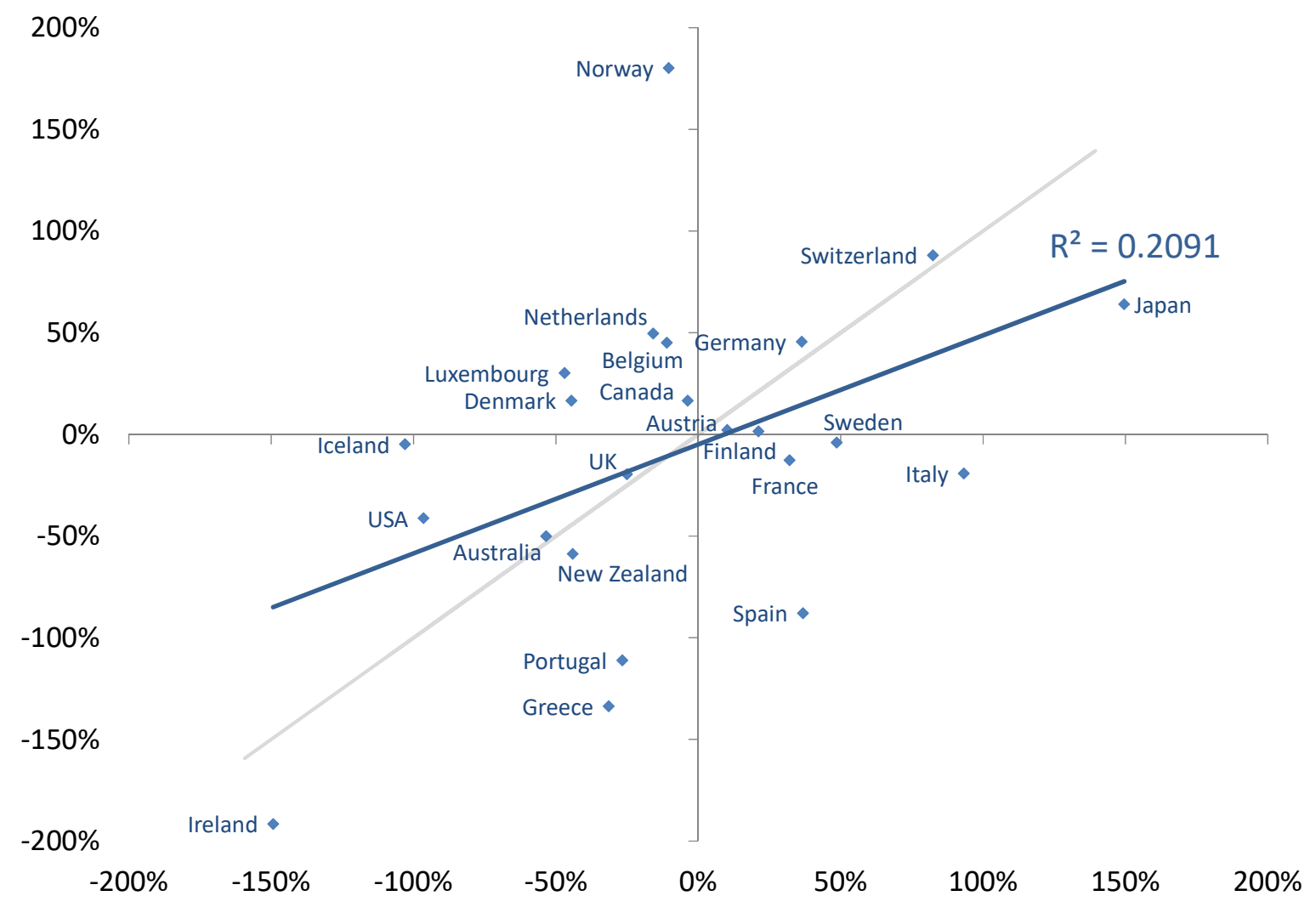

Model on $\mathrm{x}$-axis and Data on $\mathrm{y}$-axis, grey line is the 45 degree line.

Source: IMF IFS.

\subsection{Robustness and Extensions}

Having discussed the various implications of ageing population in our baseline model, we now consider some extensions to see the robustness of our results. For the sake of space, all figures are presented in Appendix C.

We begin by comparing the baseline results against a model in which we exclude housing, in order to highlight the role of housing in the baseline (see Appendix C.1). The fall in the interest rate between 1980 and 2100 is slightly larger in the model without housing: there is a $250 \mathrm{bps}$ decline compared to $233 \mathrm{bps}$ in the baseline. This reflects the role of housing as an alternative savings vehicle, which therefore mitigates the decline in interest rates. The rise in the household debt-to-GDP ratio is substantially lower, again reflecting the fact that purchasing housing in young age is an important driver of higher borrowing 
in the baseline.

We also investigate the importance of our assumption of exogenously fixed housing supply per capita, by running an alternative exercise where new housing is "produced" from the consumption good, and hence comes out of the resource constraint. This alternative assumption yields an interest rate drop of 224bps between 1980 and 2100, just 9bps smaller than the baseline. If anything, this alternative assumption reinforces the role of housing in mitigating the interest rate decline. However, the small differences between this alternative and our baseline results show that the role of housing is overall unaltered by the way it is produced or introduced in the economy, and that this assumption is not important for our results.

Second, we look at the effect of increasing the retirement age (see Appendix C.2). We compare the path of the interest rate in the baseline, in which the retirement age was held constant at age 65, to an alternative simulation in which the retirement age is held constant at age 70, holding other aspects of the calibration fixed. Since we cannot reliably calibrate labour productivity in old age, we carry out each simulation under two different assumptions about old-age productivity. The first, central, case assumes that productivity at age 65-69 is the same as at 60-64. The second, a credible upper bound, assumes that productivity remains at its peak until the end of working life, whether this is 65 or 70 .

We find that the potential effect of a higher retirement age, even as high as age 70, is fairly modest in this model, when compared to the effect that demographic changes will have on the interest rate. This is because 5 years of additional labour income is not enough to offset the rising proportion of time spent in retirement given increasing life expectancy. The extra labour supply is offset in part by more capital, such that the capital-labour ratio, and hence the interest rate, are not affected very much. Even when we assume high productivity in old age, households still face an increasing need to save while they are working in order to finance consumption in the years that they do not have any labour income.

Finally, for comparison with the literature, we use our model to consider the case of the US more specifically, as a closed economy (see Appendix C.3). The US have a more dynamic population growth than the average of advanced economies and a life expectancy below average. As expected, we find that the impact of demographic change on the interest rate in the US is smaller than for the advanced-economy average baseline. 


\section{Conclusions}

In this paper we use an overlapping-generations model, calibrated to advanced-economy data, to assess the contribution of population ageing to the fall in real interest rates and other macroeconomic trends which the world has seen over the past three decades. We find that global demographic change can explain three-quarters of the 210bps fall in global real interest rates since 1980, and larger fractions of the rises in house prices and debt. Importantly, the sign of these effects will not reverse as the baby-boom generation retires: demographic change is forecast to reduce rates by a further 46bps by 2050. Our model can also explain about $20 \%$ of the variation of advanced-economy NFA positions.

Among the many uncertainties contained in our analysis, we conclude by highlighting the three most important. The first relates to individual behaviour, and in particular the prediction in our model that households will respond to higher life expectancy with increased saving. How much of these demographic changes are actually anticipated by

households in reality? There is limited evidence in the literature showing that savings rise as life expectancy rises. De Nardi et al. (2009) use variations in life expectancy by gender, initial health and permanent income to show that higher life expectancy does lead to higher savings, but their focus is on the savings behaviour of retirees rather than workers. Similarly, both Bloom et al. (2003) and Kinugasa and Mason (2007) use crosscountry panel regressions to show that higher average life expectancy can explain higher national savings rates, but they do not address the potential reverse causation from higher wealth to higher life expectancy due to availability of health care and sanitation.

The second caveat relates to the absence of government pension schemes in our model. The implications of this simplification may vary across countries and actual pension systems. Including a fully-funded pension system would preserve the impact of ageing on aggregate savings, with pension savings supplied by pension funds instead of being directly supplied by households. Including a pay-as-you-go pension system, by redistributing from workers towards retirees via contemporaneous transfers, could reduce incentives to save in anticipation of retirement. However, the household savings in middle age will still tend to rise in response to higher life expectancy, to the extent that public pensions are insufficient to finance a households desired retirement. Conversely, maintaining a household's income throughout a longer retirement, by taxing a shrinking working population, would raise sustainability issues, and households could again revert to private savings in anticipation of lower state pension payouts in the future. 
The third uncertainty around our results relates to the global economy, and in particular to the pace and ultimate extent to which emerging markets and low-income countries integrate into world capital markets. These populations have different demographic profiles than advanced economies: they are generally much younger, although emerging markets are set to age rapidly in the coming decades. Their integration into world capital markets, either directly or indirectly through migration into advanced economies, could potentially mitigate the downward pressure on real interest rates from demographic change. On the other hand, if households or institutions in these economies have a higher propensity to save than advanced economies, they could put further downward pressure on real interest rates. 


\section{References}

Backus, D., T. Cooley, and E. Henriksen (2014). Demography and low-frequency capital flows. Journal of International Economics 92, Supplement 1, S94 - S102. 36th Annual NBER International Seminar on Macroeconomics.

Barany, Z., N. Coeurdacier, and S. Guibaud (2018, September). Capital Flows in an Aging World. CEPR Discussion Papers 13180, C.E.P.R. Discussion Papers.

Bloom, D. E., D. Canning, and B. Graham (2003). Longevity and life-cycle savings. The Scandinavian Journal of Economics 105(3), 319-338.

Caballero, R. J., E. Farhi, and P.-O. Gourinchas (2017, May). Rents, technical change, and risk premia accounting for secular trends in interest rates, returns on capital, earning yields, and factor shares. American Economic Review 107(5), 614-20.

Carvalho, C., A. Ferrero, and F. Nechio (2016). Demographics and real interest rates: Inspecting the mechanism. European Economic Review 88(C), 208-226.

De Nardi, M., E. French, and J. B. Jones (2009, May). Life expectancy and old age savings. American Economic Review 99(2), 110-15.

Domeij, D. and M. Flodén (2006, 08). Population Aging And International Capital Flows. International Economic Review 47(3), 1013-1032.

Eggertsson, G. B., N. R. Mehrotra, and J. A. Robbins (2019, January). A Model of Secular Stagnation: Theory and Quantitative Evaluation. American Economic Journal: Macroeconomics 11(1), 1-48.

Fernald, J. G. (2012). A quarterly, utilization-adjusted series on total factor productivity. Working Paper Series 2012-19, Federal Reserve Bank of San Francisco.

Gagnon, E., B. K. Johannsen, and J. D. Lopez-Salido (2016, September). Understanding the New Normal : The Role of Demographics. Finance and Economics Discussion Series 2016-080, Board of Governors of the Federal Reserve System (U.S.).

Glover, A., J. Heathcote, D. Krueger, and J.-V. Rios-Rull (2014, May). Intergenerational Redistribution in the Great Recession. Staff Report 498, Federal Reserve Bank of Minneapolis.

Goodhart, C. and M. Pradhan (2017). Demographics will reverse three multi-decade global trends. BIS Working Papers (656). 
Holston, K., T. Laubach, and J. C. Williams (2017). Measuring the natural rate of interest: International trends and determinants. Journal of International Economics $108(\mathrm{~S} 1)$, 59-75.

Jones, C. I. and P. J. Klenow (2016, September). Beyond GDP? Welfare across Countries and Time. American Economic Review 106(9), 2426-2457.

Kinugasa, T. and A. Mason (2007). Why countries become wealthy: The effects of adult longevity on saving. World Development 35(1), 1-23.

Kiyotaki, N., A. Michaelides, and K. Nikolov (2011). Winners and losers in housing markets. Journal of Money, Credit and Banking 43(2-3), 255-296.

Knoll, K., M. Schularick, and T. Steger (2017, February). No Price Like Home: Global House Prices, 1870-2012. American Economic Review 107(2), 331-353.

Krueger, D. and A. Ludwig (2007, January). On the consequences of demographic change for rates of returns to capital, and the distribution of wealth and welfare. Journal of Monetary Economics 54(1), 49-87.

Marx, M., B. Mojon, and F. R. Velde (2018, January). Why Have Interest Rates Fallen Far Below the Return on Capital. Working Paper Series WP-2018-1, Federal Reserve Bank of Chicago.

Piketty, T. and G. Zucman (2014). Capital is back: Wealth-income ratios in rich countries, 1700-2010. The Quarterly Journal of Economics 129(3), 1255-1310.

Rachel, L. and T. D. Smith (2017, September). Are Low Real Interest Rates Here to Stay? International Journal of Central Banking 13(3), 1-42.

Sajedi, R. and G. Thwaites (2016). Why are Real Interest Rates So Low? The Role of the Relative Price of Investment Goods. IMF Economic Review 64(4), 635-659.

Waldron, M. and F. Zampolli (2010, March). Household debt, house prices and consumption in the United Kingdom: a quantitative theoretical analysis. Bank of England Working Papers 379, Bank of England. 


\section{A Appendix: Additional Model Details}

\section{A.1 Bequests and non-labour income}

At each time $t$, the non-housing assets of the generations that died in the previous period must be distributed, along with the accrued interest, to living households through bequests, $B_{t}$, given by

$$
\begin{gathered}
B_{t}=\left(1+r_{t}\right) \sum_{\tau=1}^{T}\left(1-\psi_{\tau, t-\tau}\right) \tilde{\psi}_{\tau, t-\tau} s_{t-\tau} a_{\tau, t-\tau} \\
\tilde{B}_{t}=\left(1+r_{t}\right) \frac{\sum_{\tau=1}^{T}\left(1-\psi_{\tau, t-\tau}\right) \tilde{\psi}_{\tau, t-\tau} s_{t-\tau} a_{\tau, t-\tau}}{S_{t}}
\end{gathered}
$$

Similarly, the housing wealth of the agents that died in the previous period must be distributed among remaining agents. This is aggregated analogously to savings above

$$
\tilde{B}_{t}^{h}=\frac{\sum_{\tau=1}^{T}\left(1-\psi_{\tau, t-\tau}\right) \tilde{\psi}_{\tau, t-\tau} s_{t-\tau} h_{\tau, t-\tau}}{S_{t}}
$$

The additional housing endowment, added in each period to maintain a stable level of housing per capita, is added to the aggregate asset and housing bequests to form aggregate non-labour income, $\Pi_{t}$. In other words

$$
\tilde{\Pi}_{t}=\tilde{B}_{t}+p_{t}^{h} \tilde{B}_{t}^{h}+p_{t}^{h}\left(\frac{S_{t+1}}{S_{t}}-1\right) \tilde{H}
$$

\section{A.2 Calibration Procedure}

We set the parameters of the CES production function $\sigma=0.7$ and $\alpha=1 / 3$, and the annualised depreciation rate $\delta=6 \%$.

In order to set the parameters of the household's problem to match our moments, we consider a steady state of the model in which all households have the same demographic characteristics as the 1945 cohort. For a given calibration of this steady state, we run the dynamic simulations given the demographic transition, and back out the implied average life-cycle profiles in 1990-2015, and aggregate moments in the 1970s. We then adjust the calibration of the initial steady state until the moments that come out of the 
dynamic simulation match our targets from the data.

The steady state of the model gives us a stationary vector of relative population weights, $\tilde{\rho}$, with which we normalise the productivity profile such that aggregate labour productivity is 1 , that is $\tilde{\rho}^{\prime} \epsilon=1$. We set hours worked at 0.3 throughout working life, hence $l_{\tau}=0.3$ for $\tau=1, \ldots, T^{r}-1$, and $l_{\tau}=0$ for $\tau \geq T^{r}$. Hence aggregate labour supply is $L=0.3$, the value commonly used in the literature. The wage is then set as the marginal product of labour consistent with the firm's first order condition with respect to labour. Households are assumed to retire at age 65 , corresponding to $T^{r}=10$. They start receiving bequests at age $T^{b}=7$, i.e. age 50 .

We normalise the life-cycle profile of assets, $a$, such that aggregate wealth is consistent, using the firm's first order condition with respect to capital, with the annualised interest rate target of $3.42 \%$, and debt, in the first periods of life, is consistent with the debt-toGDP target of $40 \%$. Since assets in the final period of life are non-zero, we set $\phi>0$ to satisfy the first order condition with respect to $a_{T}$ for the observed level of $a_{T}$.

Finally, we normalise housing wealth over the life-cycle such that the aggregate housing stock, $\tilde{H}$, is consistent with the housing wealth-to-GDP target of $147 \%$. As mentioned above, we do not allow households to re-optimise their housing wealth in every period, and correspondingly, we use a step-wise function to fit the estimated life-cycle profile. Since this profile is found to be significantly above zero in both the first and last age groups, we set both $\tau=1$ and $\tau=T$ as "move dates" in the household's problem. In order to match the observed peak in housing wealth in middle age and subsequent fall at around age 70, we allow $\tau=5$ and $\tau=11$, corresponding to ages 40 and 70 , to also be "move dates". For simplicity, we set $\theta_{1}, \theta_{5}, \theta_{11}$ and $\theta_{T}$ to satisfy the first order condition with respect to housing with $\theta_{\tau}=0$ for all other $\tau$.

For the final step of the calibration, for a given life-cycle profile of labour and nonlabour income, housing wealth and net assets, the steady state budget constraint gives consumption over the life-cycle

$$
c_{\tau}=w l_{\tau} \epsilon_{\tau}+(1+r) a_{\tau}-a_{\tau-1}-p^{h}\left(h_{\tau}-h_{\tau-1}\right)+\pi_{\tau}
$$

Following Glover et al. (2014), we set $\beta_{1}=1$ and calibrate $\beta_{\tau}, \tau>1$, such that the Euler 
equations are satisfied given this stream of consumption

$$
\beta_{\tau}=\frac{\beta_{\tau-1}}{1+r} \frac{\tilde{\psi}_{\tau-1}}{\tilde{\psi}_{\tau}} \frac{c_{\tau}}{c_{\tau-1}}
$$

\section{A.3 Life-cycle profile data}

\section{Labour income}

We calibrate productivity to match "Wage Income" data from the SCF, which corresponds to total labour income, irrespective of hours worked. Hence, since hours worked are inelastic in the model, we are effectively subsuming all life-cycle hours and wage decisions into the productivity profile. The estimated labour income profile falls close to zero from around age 65, and in fact median wage income is exactly zero from the 65-70 age group. Hence we assume retirement begins at age 65 , that is $T^{r}=10$.

\section{Housing and non-housing wealth}

To calibrate housing wealth over the life-cycle, we take the sum of "Primary Residence" and "Other Residential Real Estate" in the SCF. The SCF includes a measure of "Net Worth" that aggregates all financial and non-financial assets and liabilities: to ensure that the profile of total net worth in the model corresponds to this observed net worth, we calibrate non-housing assets, $a$, to match the SCF "Net Worth" minus housing wealth as defined above. Note that, in this way, housing wealth measures only housing assets, and any debt related to housing, such as mortgages, are included in other assets, $a$.

\section{Data construction}

To create the life-cycle profiles for each of these variables, we put the survey respondents into 5-year age buckets corresponding to the life-cycle of households in the model, and calculate the average level of each variable for each age group, using the sampling weights provided in the SCF. This gives us an estimated life-cycle profile for each survey year from 1989-2016. We then take the average over the survey years, weighting by the number of observations in each age group in each survey year. ${ }^{29}$ This procedure gives us an estimated life-cycle profile for each of the three variables, corresponding to the average cross-sectional age profile between 1989-2016.

\footnotetext{
${ }^{29}$ Using the coefficients on the age group in fixed effects panel regressions yields similar results.
} 


\section{B Appendix: Additional Results}

\section{B.1 Drivers decomposition}

\section{Population structure and household decisions}

To decompose the changes in aggregate savings into two distinct drivers: changes in the age composition of the population and changes in the life-cycle savings decisions of each household, we proceed as follows. The baseline aggregate variables are calculated as weighted sums of the alive cohorts' per capita variables. These aggregate variables are therefore driven by the interaction of the changes in the weights of each cohort in the total population and the changes in the individual housing and saving decisions of the alive cohorts. To compute the impact of population weights only, we re-calculate the aggregate variables keeping fixed the alive cohorts' per capita variables at their 1950 level. On the opposite, to obtain the impact of optimisation decisions only, we re-calculate the aggregate variables keeping the weights fixed at their 1950 level. The results shown in Figure 8 in the paper are therefore not the outcome of a general equilibrium transition, but an ex-post decomposition. Finally, as population weights and individual household decisions multiply each other to obtain the baseline aggregate variables, it is normal that the separate effects of these two drivers do not add up to the baseline path.

Partial and general equilibrium effects

A second exercise we can carry out is to decompose the change in the life-cycle savings profile into the partial equilibrium effect of increased longevity, holding all prices constant, and the general equilibrium impact of the change in interest rates and house prices. This is shown in Figure 17, where the blue dashed lines and yellow dash-dotted lines show the general equilibrium savings and housing-wealth profiles of the 1980 and 2015 cohorts respectively, and the red solid lines show the partial equilibrium optimal savings and housing-wealth profile of the 2015 cohort if prices were held fixed at their 1980 levels.

Without any price adjustment, the 2015 cohort, which has a higher life expectancy, decides to save more and hold less housing than the 1980 cohort (comparison between the blue dashed and the red solid curves). When prices do adjust, however, the equilibrium interest rate is lower in 2015, and for the 2015 cohort saving is less attractive and borrowing in youth is more attractive, so that the desired non-housing wealth of that 
Figure 17: Counterfactual wealth and housing profiles

(a) Wealth

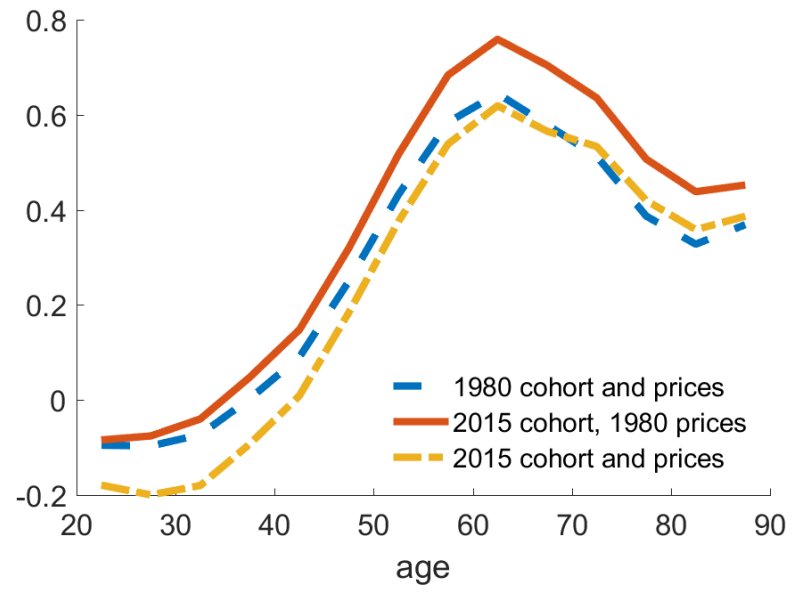

(b) Housing

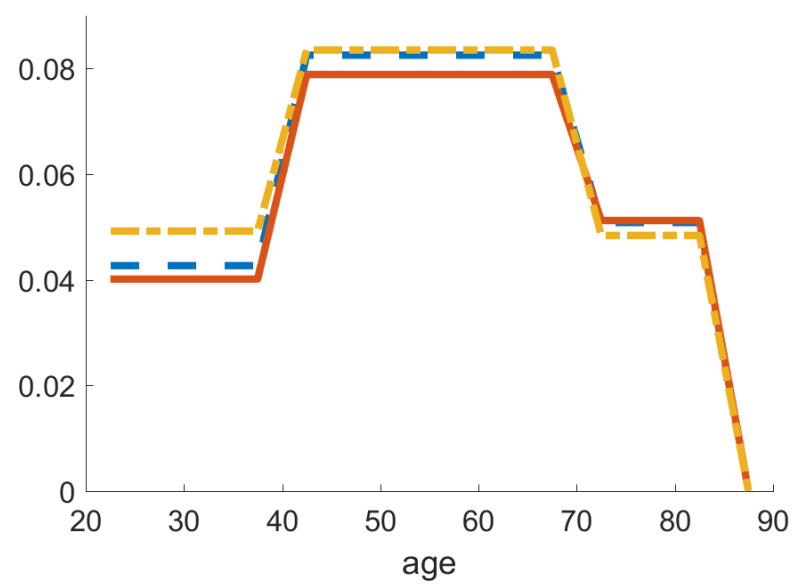

cohort is lower than that of the 1980 cohort (comparing the blue dashed and the yellow dashed-dotted curves). Conversely, as house prices rise, housing wealth is higher for the 2015 cohort.

\section{B.2 Consumption-equivalent variation and its decomposition}

Following the method developed by Jones and Klenow (2016), we calculate the proportion by which the consumption of a household born in 1950 would need to be adjusted to equalise his welfare to that of a household born at another date $t$. The intuition is the following. Take a household born at time $t$, and change his living conditions (in terms of life expectancy, share of GDP used for consumption, inequality, and so on) for the ones of a household born in 1950. To bring this household's welfare back to its initial level, we need to adjust his consumption by a certain amount. This is the consumption-equivalent variation, measured as a proportion of the consumption of a household born in 1950. A consumption-equivalent variation smaller (resp. larger) than 1 means that the household born in 1950 is better (resp. worse) off than the one born at time $t$. Similarly to Jones and Klenow (2016), we are further able to decompose this measure into various components reflecting: (i) life expectancy; (ii) consumption; (iii) housing; (iv) bequests; (v) consumption smoothing; (vi) housing smoothing and (vii) bequest smoothing. All these components are measured relative to the reference cohort born in 1950. Components (i) to (iv) are clearly positively related to the welfare of the household born at time $t$, as they directly enter the utility function. Components (v) to (vii), instead, measure the 
Figure 18: Consumption-equivalent variation and its components

(a) Total $(\lambda)$ and life expectancy component

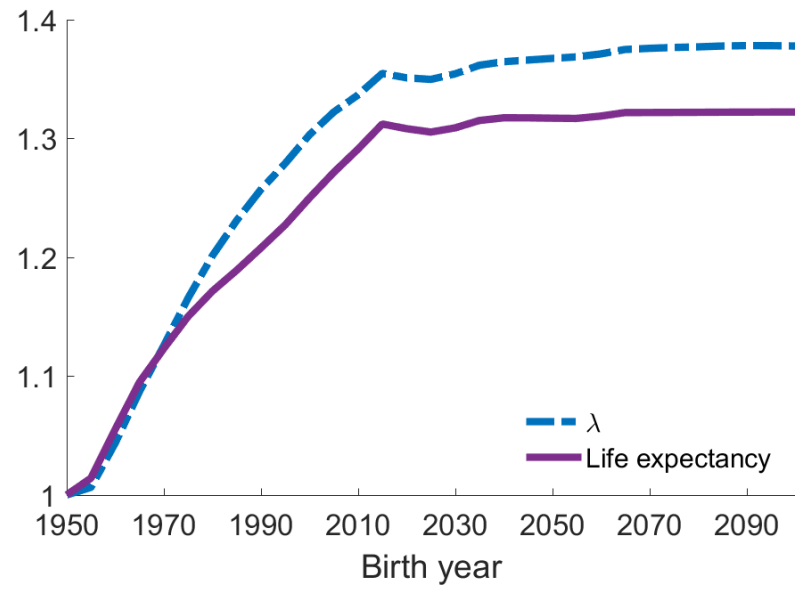

(b) Other components

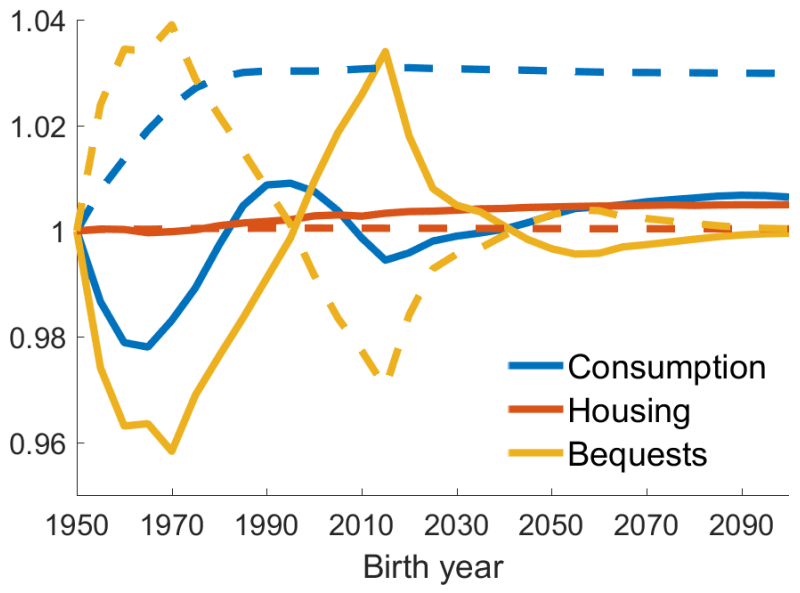

Dashed lines in panel (b) show the 'smoothing' component for each term.

difference at time $t$ between the average utility from, for example, consumption, $E(u(c))$, and the utility obtained from average consumption, $u(E(c)) .{ }^{30}$ An improved smoothing of consumption over time corresponds to a mean-preserving contraction in consumption across age groups. It keeps the utility from average consumption fixed, but increases the average utility from consumption, thus increasing the term (v) so that the relative welfare of the household born at time $t$ improves.

Figure 18 shows the evolution of this consumption-equivalent variation and its components over time. Figure 18a shows a clear welfare increase over time. The 1950 cohort's consumption would need to be increased by $13 \%$ percent to render a household born in 1970 indifferent between being born in 1970 and in 1950. This goes up to $26 \%$ for a household born in 1990 and 34\% for 2010, before stabilising towards 38\%. The purple solid line in Figure 18a shows that the main driver is life expectancy. Figure 18b further shows that the improvement in consumption smoothing in our model is the second most important driver of welfare, reflecting the same mechanisms that lowered the Gini coefficient for consumption shown in Figure 12 in the paper, while total consumption and bequest have been oscillating and tend to compensate each others. Here again, the impact of housing and housing smoothing is very limited.

\footnotetext{
${ }^{30}$ These components correspond to the ones labeled "inequality" in Jones and Klenow (2016). Given that we have one representative agent of each age in our set-up, there is no inequality within age groups, and these components only measure variations of consumption across age groups over time, and not variations of consumption within age group. We therefore prefer to interpret them as "smoothing" rather than "inequality" components.
} 
Although the effect of life expectancy appears incredibly important, there is a difficulty in including this in the welfare of different cohorts: while everything else is scale invariant, utility in death is assumed to be fixed at zero, meaning that the relative value of being alive does depend on the calibration scale, specifically if consumption, housing and bequests are above or below one. While the life expectancy component is consistently found to be a major driver of welfare over time, the precise estimation of its impact depends on the normalisation of the model. We therefore prefer to focus on its qualitative implications only. None of the other components presented in Figure 18b suffer from this conceptual problem.

\section{B.3 Open economy exercise}

Figure 19: NFA-to-GDP (\%) in the Small Open Economy Simulations

(a) United States

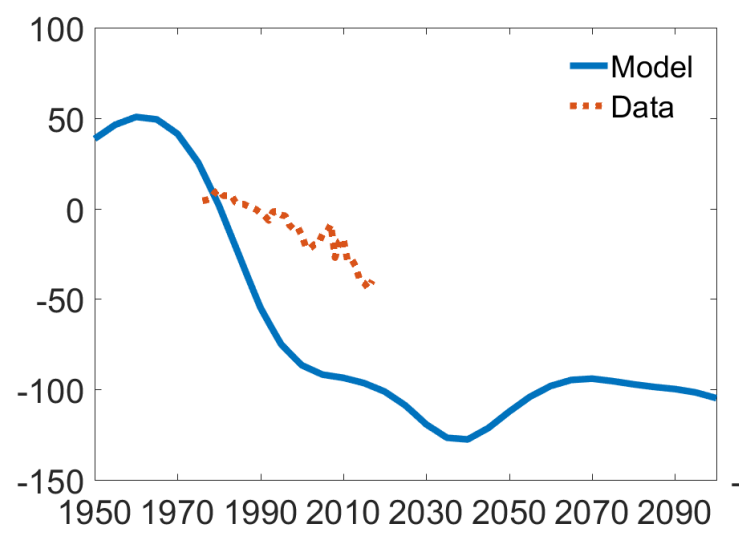

(c) Australia

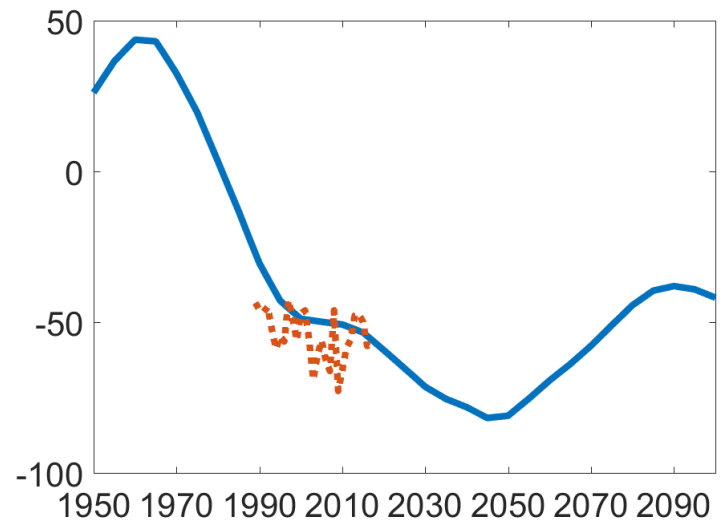

(b) United Kingdom

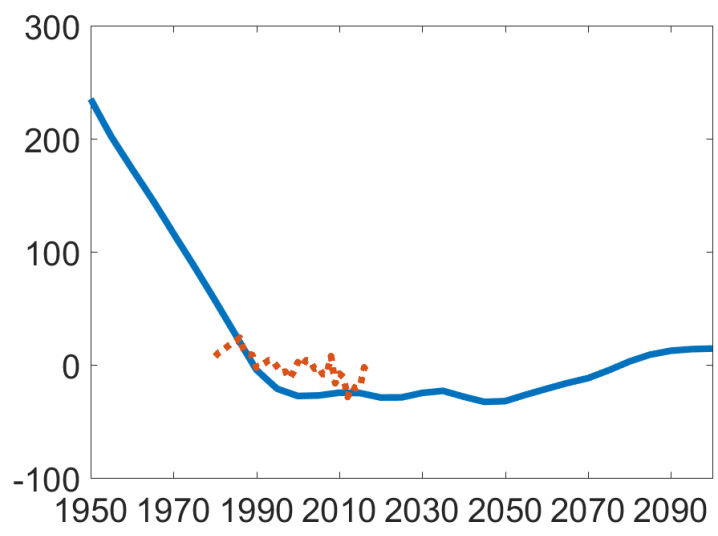

(d) Germany

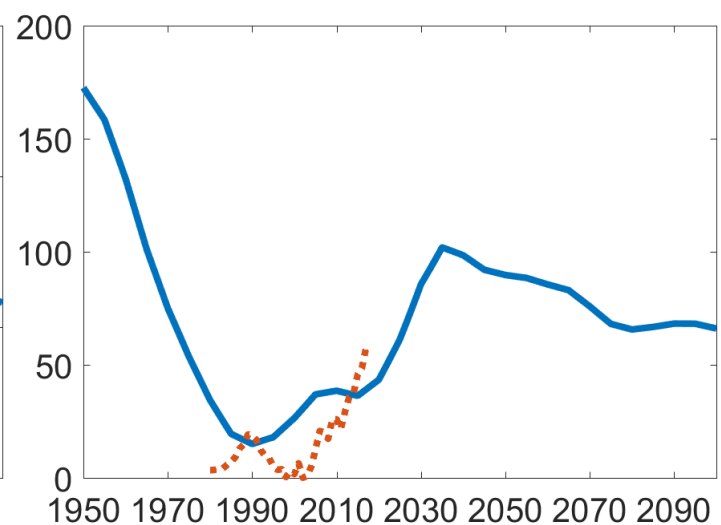

Sources: IMF IFS, authors' calculations. 
Figure 20: Demographic Changes and NFA accumulation

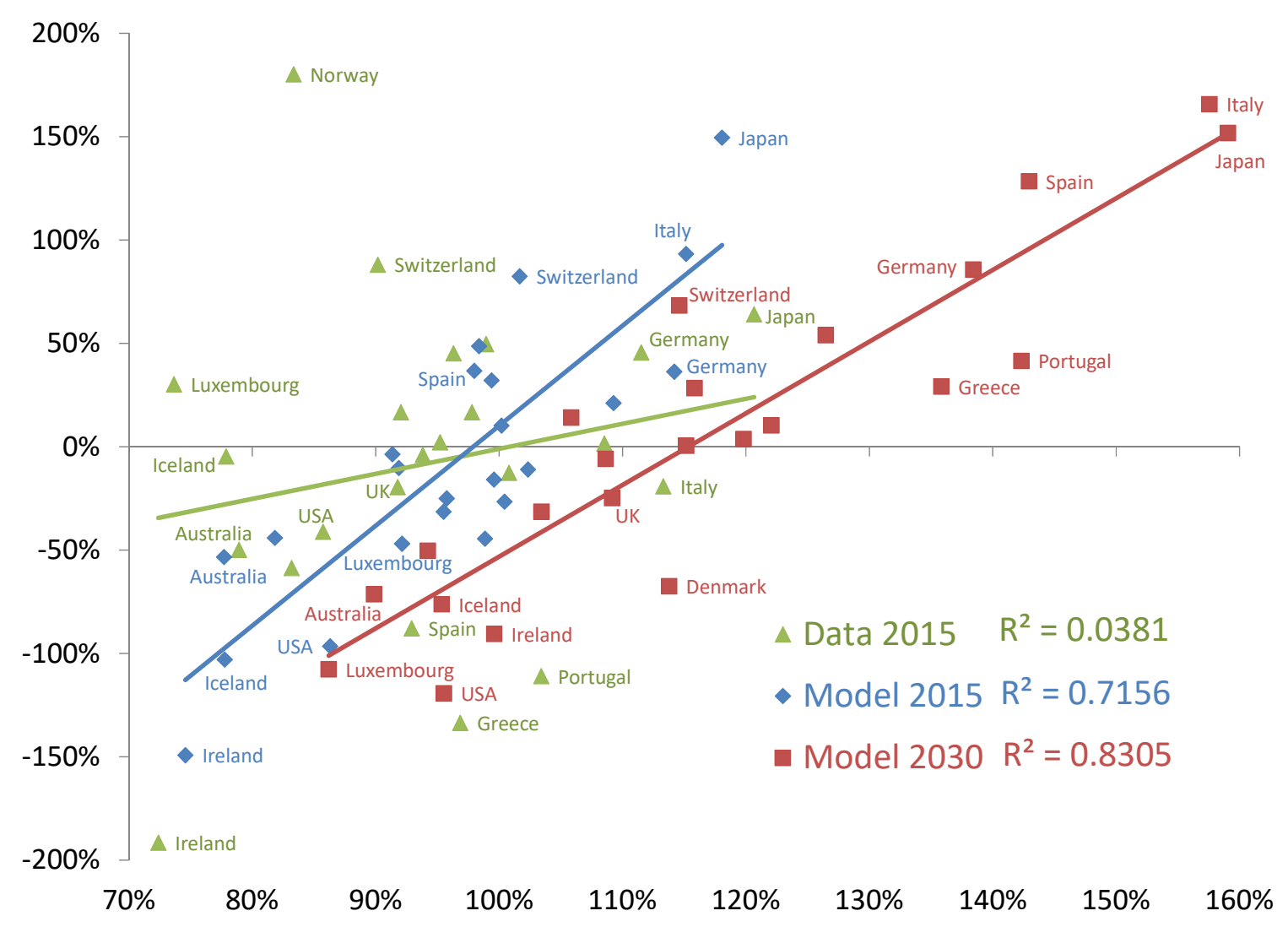

Note: HWR on x-axis and NFA-to-GDP on y-axis.

Sources: IMF IFS, UN population statistics, authors' calculations.

Using the open economy simulations described in the text, Figure 19 shows the path of the NFA for the US, UK, Australia and Germany. This simple exercise can capture the dynamics of NFAs, with Australia, the UK and the US having increasingly negative NFA positions both in the model and in the data, and Germany building up an increasingly positive NFA position. The model also suggests that the NFA position in the US and Germany will diverge further in the coming decades, as their demographic characteristics diverge from the aggregate of advanced economies, while for the UK and Australia it will remain stable.

Figure 20 plots the NFA position in 2015 against the High-wealth ratio in 2015, for the model outcome and the data, across all of the 23 countries in our aggregate advancedeconomies group. We see again that the model tends to predict a larger NFA position than observed in the data. Nonetheless, it does well to explain the cross-country pattern 
of NFA positions.

Figure 20 also includes the model predictions for NFA positions against the HWR in 2030. All countries move to the right on the HWR scale as they age. As this happens, the model predicts that some countries will move towards higher NFA positions, as they age faster than the average, while other countries will have increasingly negative NFA positions as they age more slowly than the average.

\section{Appendix: Additional Robustness and Extensions}

\section{C.1 The role of housing}

The discrete move-dates make the house price sensitive to changes in the relative size of different cohorts as they move from buying to selling housing. This means that the baby boom is important for the dynamics of house prices, as shown in Figure 21. In general equilibrium, shown in the blue line, the aggregate housing demand per capita is equal to the aggregate housing supply per capita, which is constant. This is not the case in partial equilibrium, keeping the optimal housing choice of each age cohort fixed at its 2015 level, and varying only the weight of those cohorts within the total population, shown in the red line. Clearly, this drives up the demand for housing from 1980 until 2015, while it stabilises it and drives it down from 2015 onwards.

The overall impact of housing on the model results is quantified by comparing the baseline

Figure 21: Aggregate housing demand, in general equilibrium and when only population weights are changing

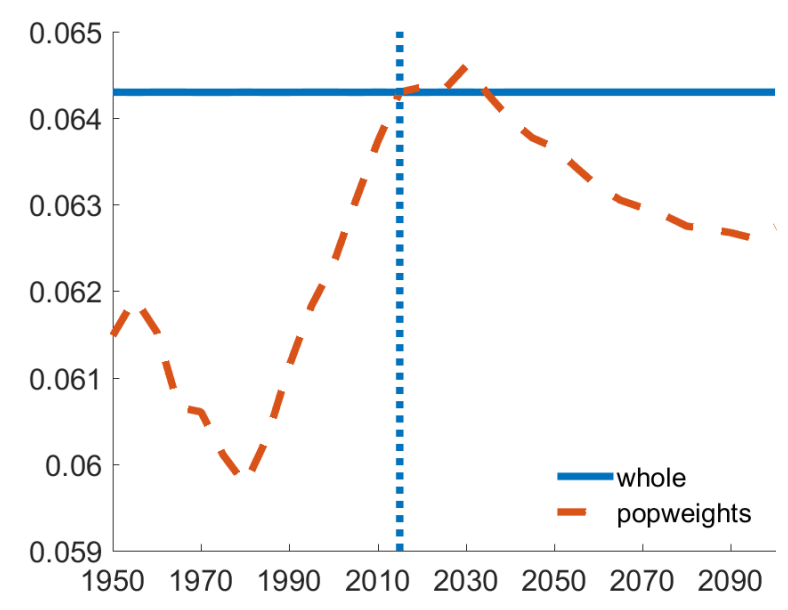


Figure 22: Simulations With and Without Housing

(a) Capital-to-GDP ratio (\%)

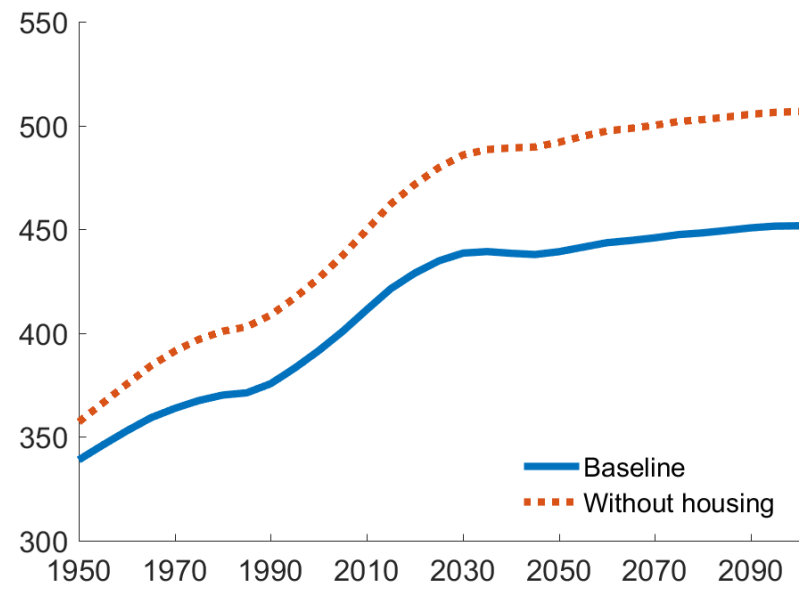

(b) Household debt-to-GDP (\%)

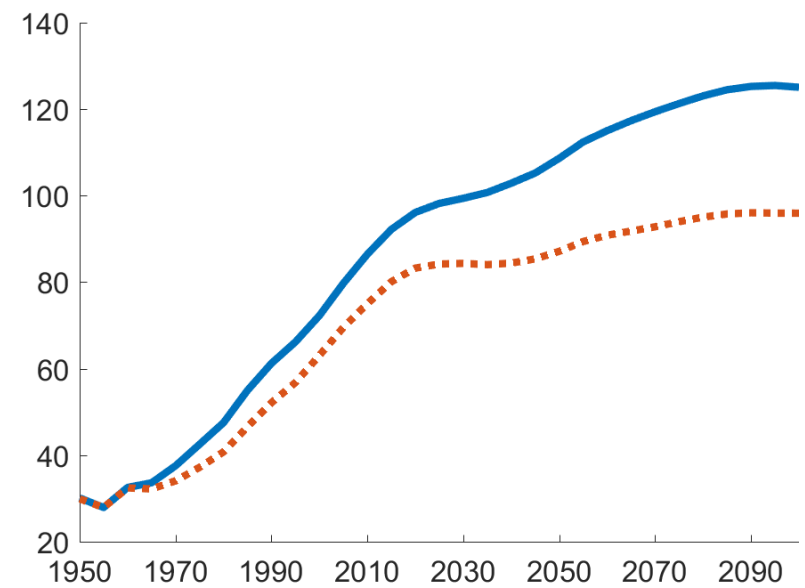

(c) Annual interest rate

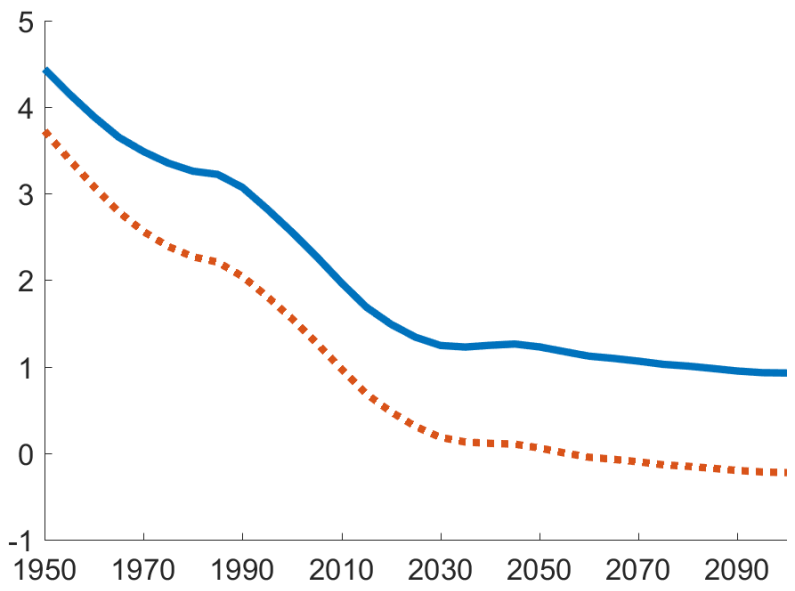

results against the results from a model in which we exclude housing. To facilitate interpretation, we keep the parameter values obtained in the baseline case to solve the model without housing. Consequently, aggregate savings and the interest rate are higher (resp. lower) over the whole transition period, and aggregate variables without housing do not match the target set in the baseline case.

The results are shown in Figure 22. As expected, the level of the capital to output ratio increases more in the absence of housing, as households do not have any alternative for transferring wealth over time. Households also accumulate less debt, as they do not need to borrow to afford housing. Given the curvature of the production function, the impact of housing on the interest rate drop is smaller than on the level of capital-to-GDP. In terms of the marginal effect of including housing in the model, the fall in the interest 
rate between 1980 to 2100 is around 250bps in the model without housing, 17bps larger than the baseline. Conversely, the rise in the household debt-to-GDP ratio over the same years is $22 \mathrm{pp}$ lower in the model without housing. Note that the presence of housing in the model prevents the interest rate from turning negative from 2060 onwards, which is not the case any more when it is excluded.

Finally, we check the robustness of our results to the assumption that the new housing stock is added exogenously to the households' non-labour income. The alternative here is to have this new housing stock coming out of the resource constraint, which implicitly means that it is being produced from the consumption good. The results of this exercise are shown in Figure 23. The differences with the baseline are negligible, showing that this assumption is not quantitatively important.

Figure 23: Simulations with New Housing Stock in Resource Constraint

$\begin{array}{ll}\text { (a) Annual real interest rate (\%) } & \text { (b) Housing price (\% deviation from } 1970 \text { baseline) }\end{array}$
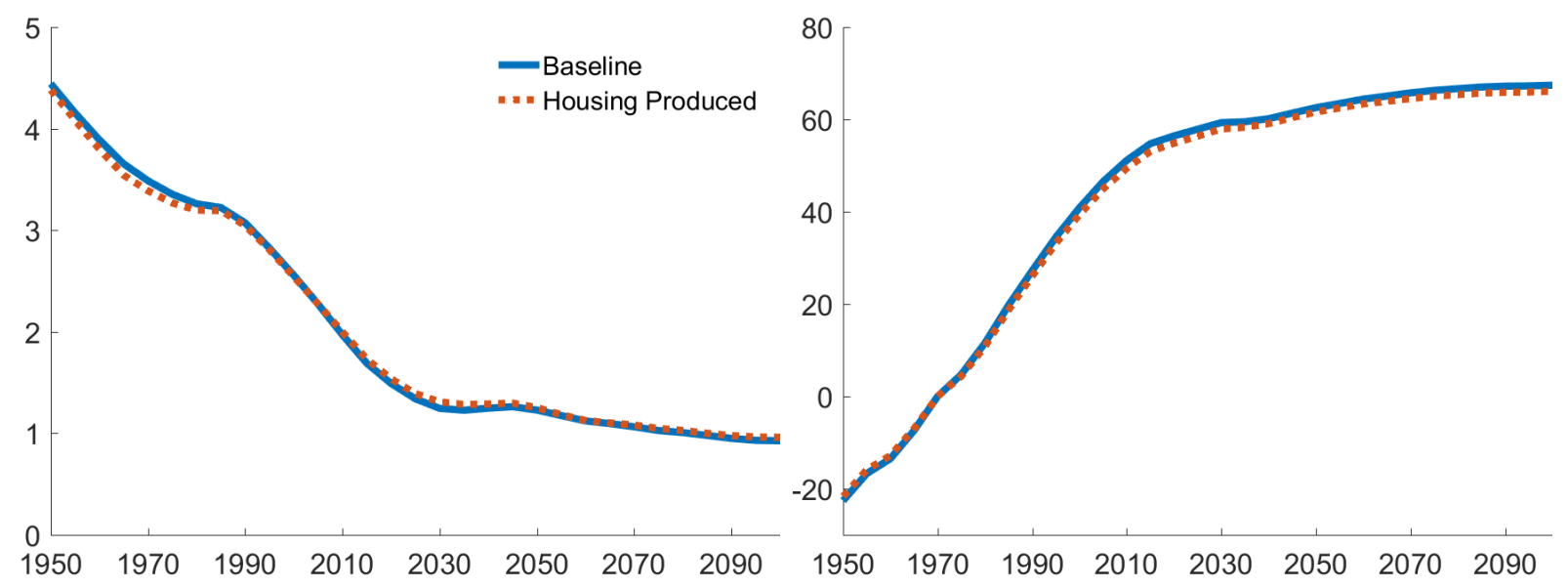

\section{C.2 Robustness: the retirement age}

The retirement age in our model is fixed at age 65 during the whole transition. Increasing the retirement age may seem more realistic, as reforms in that direction have been implemented in most advanced economies. This is likely to offset the effects of population ageing, as households spend less time in retirement for a given life expectancy.

Solving the model with a change in the retirement age during the transition requires some additional assumptions, particularly in terms of the timing of the announcement and implementation of these changes. As a first step, however, solving the model with a higher 
Figure 24: Model simulations with higher retirement age

(a) Annual real interest rate $(\%)$

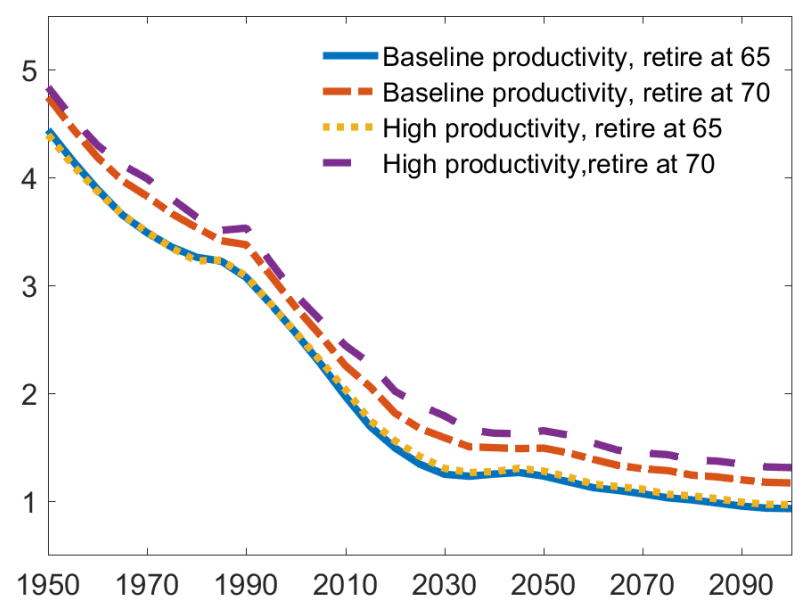

(c) Housing price (\% deviation from 1970 baseline)

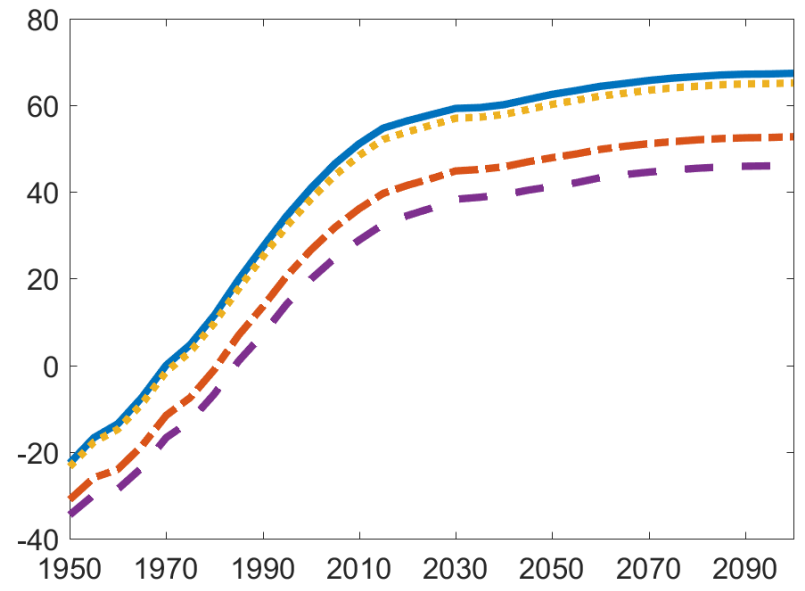

(b) Capital-to-GDP ratio (\%)

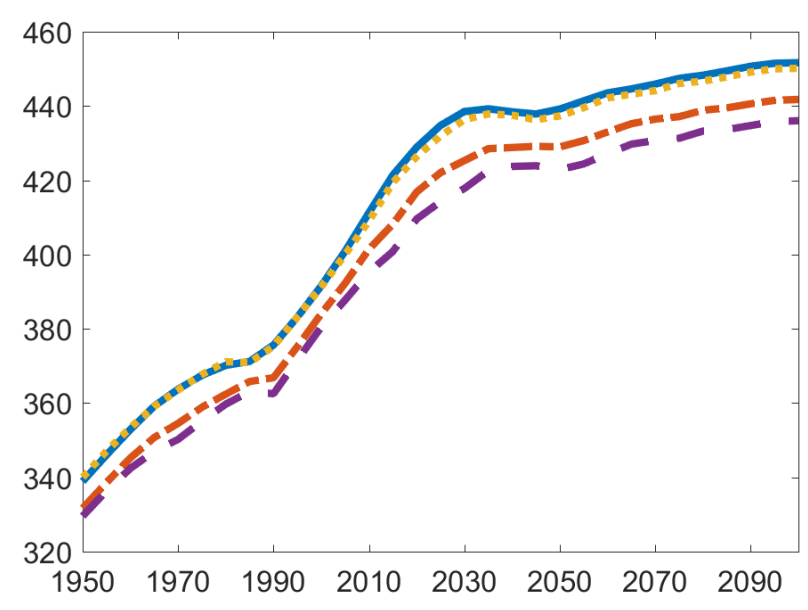

(d) Household debt-to-GDP ratio (\%)

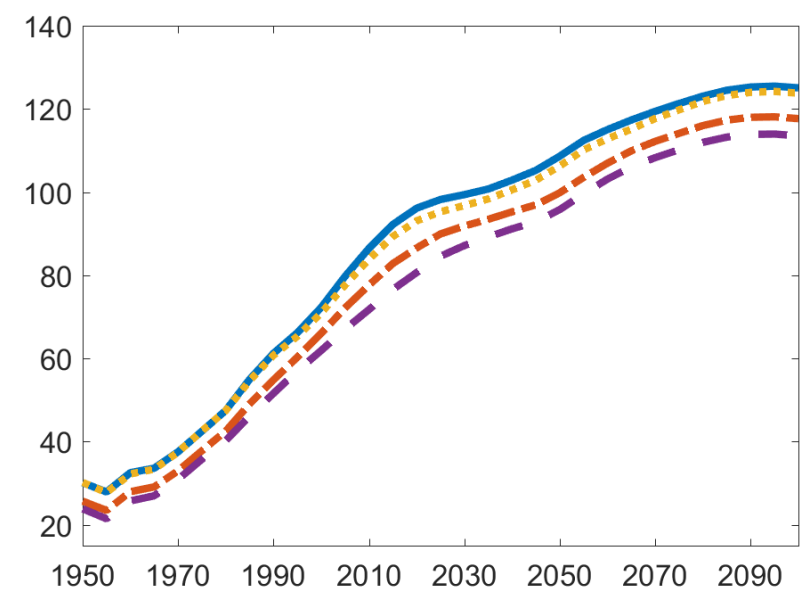


retirement age throughout the simulation can give us an insight into the importance of the retirement age. We still need to make an additional assumption about the productivity level of older workers: as a first approximation, we assume that it is the same as the 60-64 year old cohort.

When retiring at age 70 , the households save less, and the interest rate is higher. The interest rate drop between 1980 and 2050 is very similar in both cases (205bps with late retirement, against 203bps in the baseline, see Figure 24, dashed-dotted and solid lines respectively). If the retirement age were to change unexpectedly during the transition, say in 2000, the models outcome would be identical to the baseline case until 2000. After that date, the households would start progressively adjusting their saving and housing decisions to the new retirement age, to reach a final steady state identical to the one obtained with retirement at age 70 . Hence the transition would lie somewhere between these two scenarios, and at most a higher retirement age would dampen the interest rate drop by 26 bps in 2050 .

By calibrating labour productivity in our model to match labour income data, we implicitly assume that labour income changes observed in the data are entirely due to changes in labour productivity in the model. Part of the labour income decline after age 55 may however be related to a decrease in labour supply, implying that we may be underestimating the productivity of workers aged above 55. To address this, we do an additional robustness check going for the opposite extreme of assuming no productivity decline after the age 55-peak. This means that all of the decline in labor income observed in the data after age 55 is due to a decrease in labour supply, while labour productivity remains constant. We amend the calibration of the model, changing the life-cycle profile of productivity so that it stays at its highest point after age 55, and adjusting further parameters to still match the aggregate variables targets. Increasing the retirement age from 65 to 70 has a somewhat larger effect, dampening the interest rate drop between 1980 and 2050 by 37 bps (see Figure 24, dashed and dotted lines). We interpret this second robustness exercise as an upper-bound for the impact of a higher retirement age, because productivity after age 55 is set at its highest plausible level.

The potential effect of raising the retirement age even as high as 70 years old remains fairly modest in this model. An additional five years of labour income later in life does not offset the incentive to save in the highest productivity stage of life in order to smooth consumption. Furthermore, as life expectancy goes towards 90, five additional years of work have little effect on the overall proportion of life spent in retirement. Note that the 
retirement age in the UK is currently set to increase gradually from 65 to 68 by 2046 , a smaller change than the one we have assumed.

\section{C.3 Extension: The US as a closed economy}

While our main results consider the aggregate evolution of advanced economies, looking at the case of the US more specifically brings useful insights. This is true not least because much of the current literature on low interest rates, and the role of demographics, has focused on the US as a closed economy. Population ageing in the US is somewhat slower than the advanced-economy average: population growth is more dynamic and life expectancy at age 60 remains below that of advanced economies. Consequently, the old age dependency ratio doubles between 1950 and 2015 in advanced economies, while it rises by only two thirds in the US (Figure 25).

Figure 25: Demographic change in the US and AEs

(a) Annual cohort growth

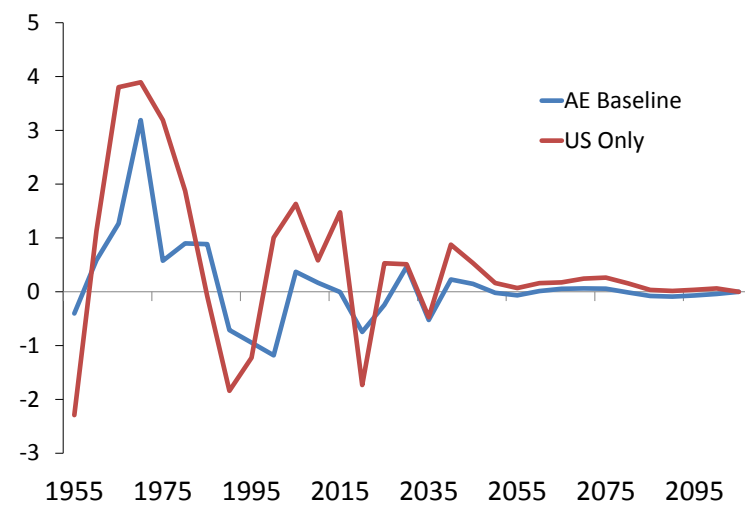

(b) OADR

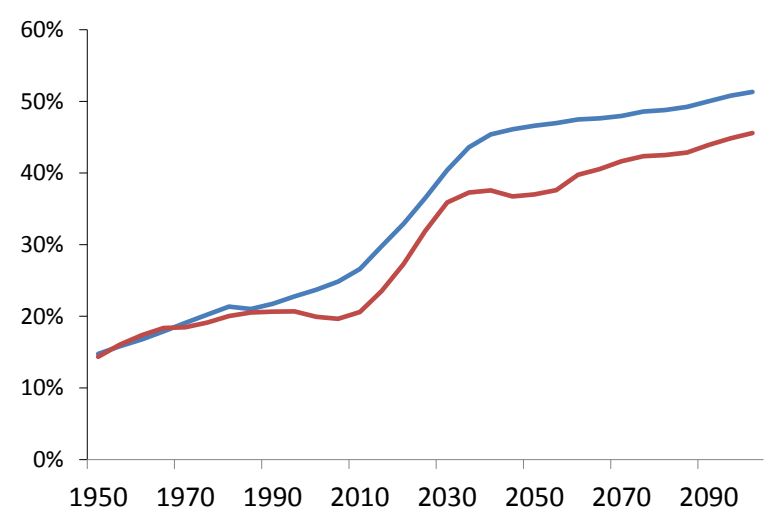

Source: UN Population Statistics

We run our model for the US as a closed economy, recalibrating the aggregate variables to match US data for the 1970s: the real interest rate, debt-to-GDP, housing wealthto-GDP are now set to $3.45 \%, 45 \%$ and $151 \%$ respectively, using the same data sources as for the baseline calibration. The life-cycle profiles for wealth and productivity were already calibrated to US data and do not change. The impact of demographic change on the interest rate is therefore smaller in the US: 136 basis points between 1980 and 2015 (see Figure 26). As the baby boom is stronger in the US, the resulting transition 
Figure 26: Simulations for the US as a Closed Economy

(a) Annual real interest rate $(\%)$

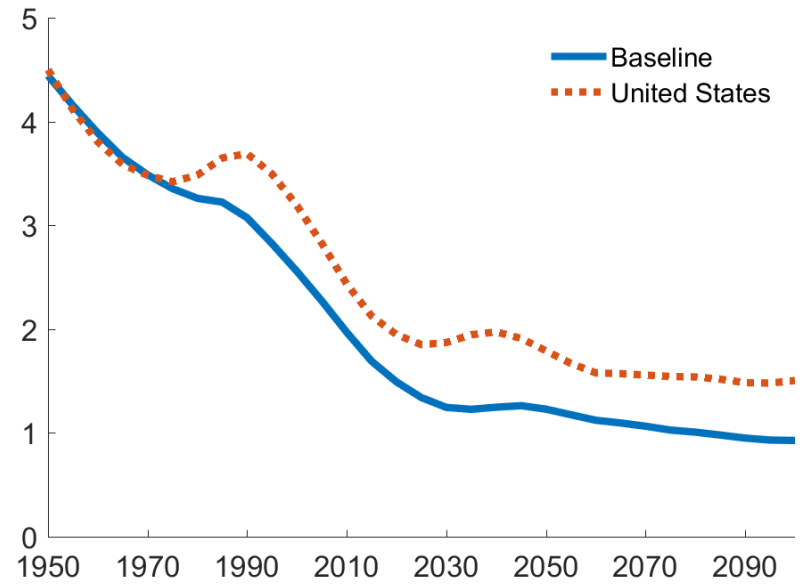

(c) Housing price (\% deviation from 1970 baseline)

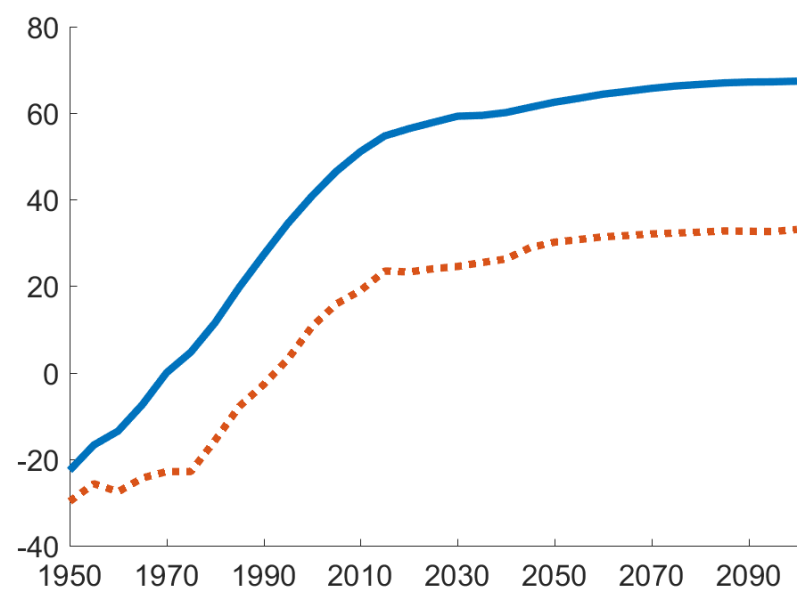

(b) Capital-to-GDP ratio (\%)

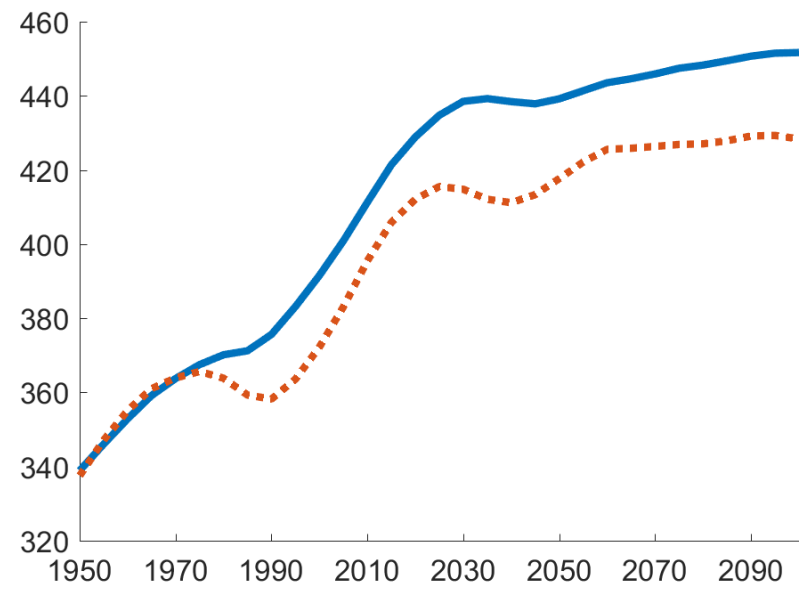

(d) Household debt-to-GDP ratio (\%)

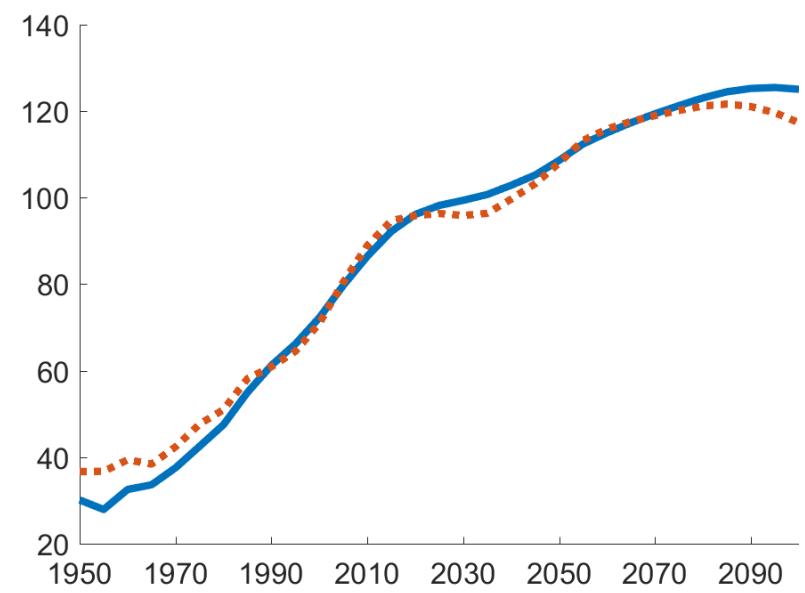

path of the interest rate is also less smooth. Similarly, the capital-to-GDP, household debt-to-GDP and housing price increase slower than in the advanced-economies case.

In the data, the US real interest rate starts from a higher point and decreases more between 1980 and 2015 relative to the advanced-economies interest rate, meaning that demographic changes explain a smaller part of the fall in the US interest rate. Over the same period, the increase in housing prices is however slower in the US than in advanced economies (Figure 27a), corresponding to the implications of the model. In terms of household debt-to-GDP ratio, the data for the US are more strongly influenced by the boom and bust of the 2000s, but it seems that the trend increase is equivalent in the US to advanced economies (Figure 27b). 
Figure 27: House prices and household debt in the US and AEs

(a) Real housing price (\% deviation from 1976)

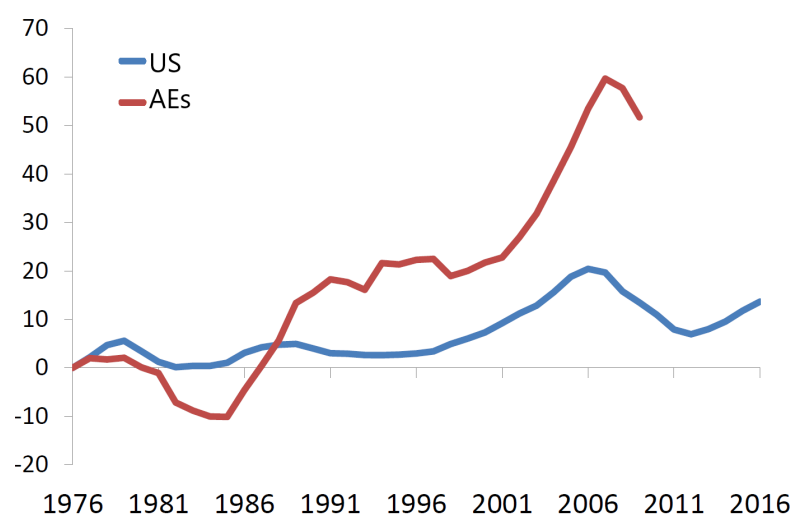

(b) Household debt-to-GDP ratio (\%)

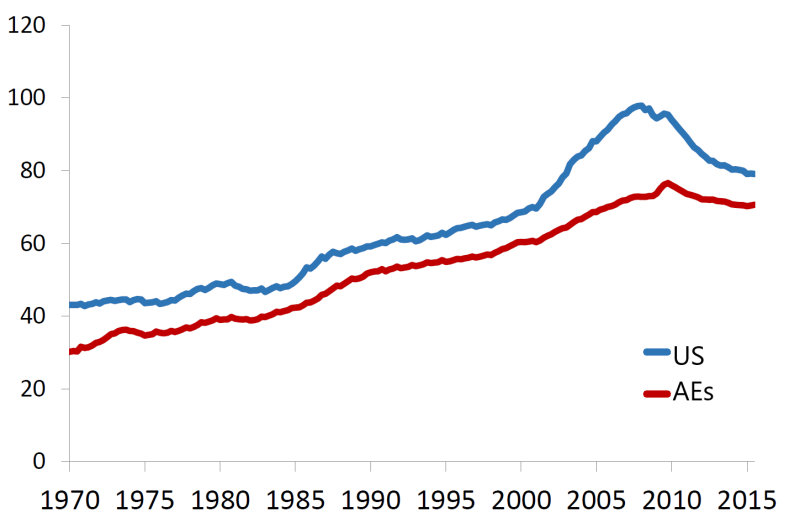

Source: BIS 